\title{
Spatial and temporal variation in river corridor exchange across a 5th-order mountain stream network
}

\author{
Adam S. Ward $^{1}$, Steven M. Wondzell ${ }^{2}$, Noah M. Schmadel ${ }^{1,3}$, Skuyler Herzog ${ }^{1}$, Jay P. Zarnetske ${ }^{4}$ Viktor Baranov $^{5,6}$, \\ Phillip J. Blaen ${ }^{7,8,9}$, Nicolai Brekenfeld ${ }^{7}$, Rosalie Chu ${ }^{10}$, Romain Derelle ${ }^{11}$, Jennifer Drummond ${ }^{7,12}$, \\ Jan H. Fleckenstein ${ }^{13,14}$, Vanessa Garayburu-Caruso ${ }^{15}$, Emily Graham ${ }^{15}$, David Hannah ${ }^{7}$ Ciaran J. Harman $^{16}$, \\ Jase Hixson $^{1}$, Julia L. A. Knapp ${ }^{17,18}$, Stefan Krause ${ }^{7}$, Marie J. Kurz ${ }^{13,19}$, Jörg Lewandowski ${ }^{20,21}$, Angang Li ${ }^{22}$, \\ Eugènia Martí ${ }^{12}$, Melinda Miller ${ }^{1}$, Alexander M. Milner ${ }^{7}$, Kerry Neil ${ }^{1}$, Luisa Orsini ${ }^{11}$, Aaron I. Packman ${ }^{22}$, \\ Stephen Plont ${ }^{4,23}$, Lupita Renteria ${ }^{24}$, Kevin Roche ${ }^{25}$, Todd Royer ${ }^{1}$, Catalina Segura ${ }^{26}$, James Stegen ${ }^{15}$, \\ Jason Toyoda ${ }^{10}$, Jacqueline Wells ${ }^{24}$, and Nathan I. Wisnoski ${ }^{27}$ \\ ${ }^{1}$ O'Neill School of Public and Environmental Affairs, Indiana University, Bloomington, Indiana, USA \\ ${ }^{2}$ USDA Forest Service, Pacific Northwest Research Station, Corvallis, Oregon, USA \\ ${ }^{3}$ USGS Earth Surface Processes Division, U.S. Geological Survey, Reston, Virginia, USA \\ ${ }^{4}$ Department of Earth and Environmental Sciences, Michigan State University, East Lansing, Michigan, USA \\ ${ }^{5}$ LMU Munich Biocenter, Department of Biology II, Großhaderner Str. 2, 82152 Planegg-Martinsried, Germany \\ ${ }^{6}$ Department of River Ecology and Conservation, Senckenberg Research Institute and Natural History Museum, \\ 63571 Gelnhausen, Germany \\ ${ }^{7}$ School of Geography, Earth \& Environmental Sciences, University of Birmingham, Edgbaston, Birmingham, B15 2TT, UK \\ ${ }^{8}$ Birmingham Institute of Forest Research (BIFoR), University of Birmingham, Edgbaston, Birmingham, B15 2TT, UK \\ ${ }^{9}$ Yorkshire Water, Halifax Road, Bradford, BD6 2SZ, UK \\ ${ }^{10}$ Environmental Molecular Sciences Laboratory, Pacific Northwest National Laboratory, Richland, Washington, USA \\ ${ }^{11}$ Environmental Genomics Group, School of Biosciences, the University of Birmingham, Birmingham, B15 2TT, UK \\ ${ }^{12}$ Integrative Freshwater Ecology Group, Centre for Advanced Studies of Blanes (CEAB-CSIC), Blanes, Spain \\ ${ }^{13}$ Dept. of Hydrogeology, Helmholtz Center for Environmental Research - UFZ, Permoserstraße 15, 04318 Leipzig, Germany \\ ${ }^{14}$ Bayreuth Center of Ecology and Environmental Research, University of Bayreuth, 95440 Bayreuth, Germany \\ ${ }^{15}$ Earth and Biological Sciences Division, Pacific Northwest National Laboratory, Richland, Washington, USA \\ ${ }^{16}$ Department of Environmental Health and Engineering, Johns Hopkins University, Baltimore, Maryland, USA \\ ${ }^{17}$ Department of Environmental Systems Science, ETH Zürich, Zurich, Switzerland \\ ${ }^{18}$ Center for Applied Geoscience, University of Tübingen, Tübingen, Germany \\ ${ }^{19}$ The Academy of Natural Sciences of Drexel University, Philadelphia, Pennsylvania, USA \\ ${ }^{20}$ Leibniz Institute of Freshwater Ecology and Inland Fisheries, Department of Ecohydrology, \\ Müggelseedamm 310, 12587 Berlin, Germany \\ ${ }^{21}$ Humboldt University Berlin, Geography Department, Rudower Chaussee 16, 12489 Berlin, Germany \\ ${ }^{22}$ Department of Civil and Environmental Engineering, Northwestern University, Evanston, Illinois, USA \\ ${ }^{23}$ Department of Biological Sciences, Virginia Polytechnic Institute and State University, Blacksburg, Virginia, USA \\ ${ }^{24}$ Pacific Northwest National Laboratory, Richland, Washington, USA \\ ${ }^{25}$ Department of Civil \& Environmental Engineering \& Earth Sciences, University of Notre Dame, Notre Dame, Indiana, USA \\ ${ }^{26}$ Forest Engineering, Resources, and Management, Oregon State University Corvallis, Oregon, USA \\ ${ }^{27}$ Department of Biology, Indiana University, Bloomington, Indiana, USA
}

Correspondence: Adam S. Ward (adamward@indiana.edu)

Received: 8 March 2019 - Discussion started: 23 April 2019

Revised: 26 August 2019 - Accepted: 15 October 2019 - Published: 20 December 2019

Published by Copernicus Publications on behalf of the European Geosciences Union. 


\begin{abstract}
Although most field and modeling studies of river corridor exchange have been conducted at scales ranging from tens to hundreds of meters, results of these studies are used to predict their ecological and hydrological influences at the scale of river networks. Further complicating prediction, exchanges are expected to vary with hydrologic forcing and the local geomorphic setting. While we desire predictive power, we lack a complete spatiotemporal relationship relating discharge to the variation in geologic setting and hydrologic forcing that is expected across a river basin. Indeed, the conceptual model of Wondzell (2011) predicts systematic variation in river corridor exchange as a function of (1) variation in baseflow over time at a fixed location, (2) variation in discharge with location in the river network, and (3) local geomorphic setting. To test this conceptual model we conducted more than 60 solute tracer studies including a synoptic campaign in the 5th-order river network of the H. J. Andrews Experimental Forest (Oregon, USA) and replicate-intime experiments in four watersheds. We interpret the data using a series of metrics describing river corridor exchange and solute transport, testing for consistent direction and magnitude of relationships relating these metrics to discharge and local geomorphic setting. We confirmed systematic decrease in river corridor exchange space through the river networks, from headwaters to the larger main stem. However, we did not find systematic variation with changes in discharge through time or with local geomorphic setting. While interpretation of our results is complicated by problems with the analytical methods, the results are sufficiently robust for us to conclude that space-for-time and time-for-space substitutions are not appropriate in our study system. Finally, we suggest two strategies that will improve the interpretability of tracer test results and help the hyporheic community develop robust datasets that will enable comparisons across multiple sites and/or discharge conditions.
\end{abstract}

\section{Introduction}

Ecological functions and processes in the river corridor are influenced by the exchange of water, solutes, and energy between the surface stream and its catchment and thus regulate downstream water quality (e.g., Brunke and Gonser, 1997; Krause et al., 2011; Wondzell and Gooseff, 2014; Ward, 2015). These exchange fluxes are collectively termed river corridor exchange and integrate the stream, hyporheic zone, and riparian zone along the river network (Harvey and Gooseff, 2015). Several recent studies have extended feature- and reach-scale findings to predict ecological functions of river corridors at basin scales relevant to resource management (e.g., Gomez-Velez and Harvey, 2014; Kiel and Cardenas, 2014; Gomez-Velez et al., 2015; Bertuzzo et al., 2017; Helton et al., 2018). These approaches require a scaling rela- tionship to predict river corridor exchange across space and through time. Discharge is a logical scaling factor and has been studied as a control on river corridor exchange in both space (i.e., along a network) and time (i.e., under different hydrologic conditions at a fixed location). However, discharge integrates forcing at different scales and may not lead to consistent predictions of river corridor exchange (Ward and Packman, 2019). For example, increases in discharge have been found to cause increases, decreases, or no change in river corridor exchange (Morrice et al., 1997; Butturini and Sabater, 1999; Hart et al., 1999; Jin and Ward, 2005; Wondzell, 2006, 2011; Zarnetske et al., 2007; Schmid, 2008; Karwan and Saiers, 2009; Schmid et al., 2010; Fabian et al., 2011; Ward et al., 2013a). Clearly, to use discharge as a scaling factor to predict river corridor exchange, a more complete description of the exchange-discharge relationship is required.

River corridor exchange is broadly understood to be controlled by interactions between hydrologic forcing and geomorphic setting (Kasahara and Wondzell, 2003; Ward et al., 2012). First, hydrologic forcing encompasses variation in the catchment wetness and storage during storms (Ward et al., 2013a; Dudley-Southern and Binley, 2015; Malzone et al., 2016), seasonal baseflow recession (Payn et al., 2009; Voltz et al., 2013; Ward et al., 2013c; Schmadel et al., 2017), and diurnal fluctuations arising from natural (e.g., Harman et al., 2016; Musial et al., 2016) or anthropogenic (e.g., Sawyer et al., 2009; Gerecht et al., 2011) controls. While hydrologic forcing reflects a variation in the temporal domain, the geomorphic setting is typically assumed static during river corridor exchange studies. Thus, repeated studies under different discharge conditions are focused on predicting river corridor exchange as a function of hydrologic forcing and used to develop exchange-discharge relationships at individual study reaches (e.g., Rana et al., 2017). This strategy yields a fixed-in-space, varied-in-time exchange-discharge relationship. Notably, most classical expectations are based on differing steady discharge conditions (e.g., high vs. low baseflow), though an emerging body of field studies (detailed above), modeling studies (e.g., Malzone et al., 2016; Schmadel et al., 2016b), and conceptual models (e.g., Fig. 8 in Ward et al., 2016) are beginning to actively address exchange during unsteady discharge conditions. It is also important to note that, in some cases, changes in discharge can also change the effective geomorphic setting. For example, increases in discharge can flood pool-riffle sequences (e.g., Storey et al., 2003; Church and Zimmerman, 2007) or activate secondary channels (e.g., Ward et al., 2016). Exchange-discharge relationships during steady flow conditions have been examined in many studies with repeated studies over time at a single site resulting in both positive and negative correlations between river corridor exchange and discharge (Ward and Packman, 2019), though one classic expectation is decreased 
exchange with increased discharge due to compression of hyporheic flow paths by toward-stream hydraulic gradients (e.g., Hakenkamp et al., 1993; Hynes, 1983; Palmer, 1993; Vervier et al., 1992; White et al., 1993).

The second primary control on river corridor exchange is the geomorphic setting, including differences attributable to tectonics (e.g., Valett et al., 1996; Payn et al., 2009). Over geologic timescales the geomorphic setting has coevolved with hydrologic forcing. For example, as drainage area and discharge accumulate through mountain stream networks, we expect predictable spatial patterns including lower slopes, smaller grain size, larger channel width-to-depth ratios, and increased valley bottom widths (e.g., Leopold and Maddock, 1953; Wohl and Merritt, 2005, 2008; Brardinoni and Hassan, 2007). The evolution of geologic setting occurs over an extremely long timescale, allowing the common simplification of assuming geologic setting as static in hyporheic studies. As a result of this assumption, researchers commonly conduct experiments across a spatial gradient to describe patterns in river corridor exchange (Payn et al., 2009; Covino et al., 2011; Mallard et al., 2014). This approach provides a fixed-in-time, varied-in-space river corridor exchange-discharge relationship that describes a network under a fixed hydrologic condition, most commonly baseflow. Wondzell (1994) suggested that exchange should decrease with increasing watershed size based on first principles. For example, the potential maximum exchange is limited by the streambed area, indicating that the ratio of wetted perimeter to discharge $(Q)$ should be correlated to the maximum possible exchange per unit length of stream channel. As $Q$ increases more rapidly than wetted perimeter as watersheds increase in size, the amount of exchange should be expected to decrease. In fact, most studies have identified a decreasing role of river corridor exchange as river basins increase in size, attributable to less exchange flux relative to stream flow (Stewart et al., 2011; Mallard et al., 2014; Gomez-Velez and Harvey, 2014; Kiel and Cardenas, 2014; Gomez-Velez et al., 2015; Ward et al., 2018a).

To explain spatiotemporal patterns in river corridor exchange from headwaters to large rivers, Wondzell (2011) developed a conceptual framework describing the relative importance of river corridor exchange to reach-scale transport (i.e., hyporheic exchange flow normalized by river discharge, $Q_{\mathrm{HEF}} / Q$ ), spanning three primary dimensions. First, $Q_{\mathrm{HEF}} / Q$ would be largest under the lowest steadystate discharge conditions, where subsurface flow may reflect a larger proportion of total down-valley flow. Second, $Q_{\mathrm{HEF}} / Q$ would be largest in the headwaters and decrease moving toward larger river segments as described above. Lastly, Wondzell (2011) characterized the local geomorphic setting at an individual study site as "hyporheic potential," combining valley slope and hydraulic conductivity to reflect local controls on exchange at the reach scale that might vary locally within the systematic spatial and temporal dimensions. Larger hyporheic potential was associated with larger
$Q_{\mathrm{HEF}} / Q$. Subsequently, Harvey et al. (2018) suggested that hydrologic connectivity (i.e., $Q_{\mathrm{HEF}} / Q$ ) is a primary water quality regulator. Ward et al. (2018a) further extended this concept to account for changes in valley bottom width and depth of colluvium, describing the down-valley capacity of the valley bottom to transmit water estimated via Darcy's law. Unlike the first two dimensions, hyporheic potential may not have a predictable trend as one moves down a river continuum because decreasing slopes and hydraulic conductivities may be offset by larger hyporheic cross sections.

Efforts to predict river corridor exchange and associated ecosystem processes as a function of geomorphic setting and hydrologic forcing have been implemented in large-scale remotely sensed test cases. However, this method still lacks field validation across varying discharge and across a range of stream types with varying morphologic features. For example, Gomez-Velez and Harvey (2014) and Gomez-Velez et al. (2015) used the Networks with EXchange and Subsurface Storage (NEXSS) model to describe spatial patterns in exchange in low-gradient alluvial river networks. NEXSS is based on steady-state discharge and bed sediment grain size as a proxy for local morphologic control. While this modeling approach has demonstrated the importance of river corridor exchange in large river basins, it is built on scaling relationships derived from idealized mechanistic and conceptual models that may not be representative of headwater streams. Further, the model results have yet to be confirmed in field trials.

To our knowledge, only the field study of Payn et al. (2009) explicitly considered both spatial and temporal dimensions of the exchange-discharge relationship. The results of that study were broadly consistent with the conceptual model of Wondzell (2011). However, we now understand that fixed reach lengths cause systematic decreases in the "window of detection" (the timescale of exchange flow paths that are measurable with tracer studies; Harvey et al., 1996; Wagner and Harvey, 1997; Harvey and Wagner, 2000). The systematic decrease in window of detection with increasing discharge along the study stream would have interacted with the fixed reach lengths, likely leading to the underestimation of $Q_{\mathrm{HEF}}$ at high discharges. As a result, it is difficult to separate the observed process from limitations of the measurement instrument (see discussion of the data of Payn et al. in Ward et al., 2013b, and similar studies by Schmadel et al., 2016a).

Several other studies have found general agreement with the prediction of Wondzell (2011) of decreasing $Q_{\mathrm{HEF}} / Q$ with increasing baseflow through space and at individual study reaches (Kelleher et al., 2013; Patil et al., 2013; Ward et al., 2013c). Thus, the conceptual model of Wondzell (2011) might provide an organized framework to extend reach-scale results across space and time in mountain river basins. However, the studies cited above were limited to headwater networks, whereas Wondzell (2011) suggested patterns should hold across much larger scales and geomorphic settings. To 
date, the conceptual model of Wondzell (2011) lacks validation across large river basins studied with a systematic field approach. Given the variability of reach-scale river corridor exchange trends documented in the literature (see summary in Ward and Packman, 2019), it is critical to test the conceptual model of Wondzell (2011) with field data that cover much more of the space-time parameter space.

In this study, we seek to characterize river corridor exchange in a mountain stream network as a function of (1) variation in baseflow at a fixed location through seasonal recession, (2) variation in discharge as a function of drainage area during a fixed baseflow condition, and (3) local geomorphic setting (quantified here as hyporheic potential). This study will directly test the conceptual model posed by Wondzell (2011) for mountain stream networks. If the conceptual relationships can be confirmed, this would enable transferability of findings from feature- and reach-scale studies to entire networks of high-gradient mountain streams, paralleling recent advances in low-gradient river networks (e.g., Gomez-Velez and Harvey, 2014; Kiel and Cardenas, 2014; Gomez-Velez et al., 2015). Further, confirmation of the conceptual model would provide a simple scaling relationship for time-variable discharge, which has not been possible to date. In this study, we conducted a series of solute tracer studies to construct temporal exchange-discharge relationships (i.e., a fixed study reach with observations spanning a range in discharge) and spatial exchange-discharge relationships (i.e., a synoptic campaign to measure exchange at many locations under summer baseflow discharge) for a 5th-order mountain river network, together with physical observations (including hydraulic conductivity, drainage area, slope, valley bottom width, sinuosity) to also characterize hyporheic potential. We interpret the data using a series of metrics describing river corridor exchange and their relationships to discharge.

\section{Methods}

\subsection{Field site and solute tracer experiments}

\subsubsection{Site description}

The H. J. Andrews Experimental Forest (HJA) is a 5th-order basin draining about 6400 ha in the western Cascade Mountains, Oregon, USA, with elevations ranging from about 410 to $1630 \mathrm{~m}$ a.m.s.l. The basin is heavily forested and includes stands of old growth Douglas fir trees as well as smaller areas that have been logged to study the effects of forest management practices. Additional details about the climate, morphology, geology, and ecology of the site are well described by others (Dyrness, 1969; Swanson and James, 1975; Swanson and Jones, 2002; Jefferson et al., 2004; Cashman et al., 2009; Deligne et al., 2017). The synoptic sampling spanned the entire HJA basin to characterize basin-scale valley bot- tom conditions, while additional, more detailed sampling occurred in three distinct landform types.

Headwater sites in the HJA generally fall into one of three landform types associated with underlying geology and geomorphic processes (Table 1). We selected four 2ndorder basins to establish fixed stream reaches for replication through the summer baseflow recession period, one in each landform type plus one replicate. The first landform type occurs in the lower elevations of the HJA where geology is dominated by upper Oligocene-lower Miocene basaltic flows. These volcanoclastic rocks were weakened by hydrothermal alteration from subsequent volcanic activity, enabling rapid downcutting and formation of a highly dissected landscape. Hillslopes are steep; valleys are v-shaped and tend to be narrow with steep longitudinal gradients. Valley bottom colluvium is typically shallow but variable, being emplaced by hillslope mass wasting and debris flows. Exposed bedrock is visible in many locations, while deeper deposits form behind individual large logs or larger log jams. We selected the well-studied Watersheds 1 and 3 (WS01 and WS03) for two of our fixed reaches (Fig. 1). Briefly, WS01 and WSO3 valley bottoms reflect different time periods in this landform. In 1996, WS03 was scoured to bedrock along hundreds of meters of the valley bottom (Johnson, 2004). Since that time no debris flows have been recorded, resulting in a study reach nearly free of colluvium in the upper half of the study reach. WS01 is a paired catchment to WS03, reasonably representing a pre-scour and less-constrained comparison to WS03. WS01 has a wood-forced step-pool morphology (Montgomery and Buffington, 1997, 1998) over most of its main stem length, representative of many steep mountain streams. River corridor exchange in the two catchments has been broadly studied using a paired catchment approach (e.g., Wondzell, 2006; Voltz et al., 2013; Ward et al., 2017b).

Deep-seated earth flows provide a second contrasting landform type in the HJA. These are emplaced on the upper Oligocene-lower Miocene basaltic flows and are characterized by a poorly developed channel network (many parallel channels), a general lack of lateral contributing area to the river corridor, little lateral constraint, and extensive colluvial deposits with no bedrock exposure. Based on visual inspection, channels on these earthflows are actively meandering, braiding, and downcutting. Characteristic geomorphic features include meander bends and cutbanks (visually similar to lower-gradient alluvial systems of the region) in addition to step-pool features. We selected an unnamed 2nd-order reach on a large earth flow adjacent to WS03 for this study (Fig. 1).

The third landform type occurs in high-elevation headwater catchments with U-shaped valleys characteristic of glacial cirques, which formed in plieocascade volcanics. Valley bottoms are filled with compacted glacial tills. Large wood atop the till forms pools and steps with intermediate gravel and cobble riffles. Lateral tributary area is relatively uniform along the valley with few hollows or tributary valleys (in con- 
Table 1. Summary of key characteristics of the fixed-reach sites. See detailed descriptions for further information (Dyrness, 1969; Swanson and James, 1975; Swanson and Jones, 2002; Jefferson et al., 2004; Cashman et al., 2009; Deligne et al., 2017).

\begin{tabular}{lll}
\hline Site & Important hydrologic controls & Important geologic controls \\
\hline WS01 & - Highly dissected landscape & - Colluvium deposited by debris flows from hillslopes \\
& - Focused lateral inflows & forms extensive deposits in the valley bottom \\
& - Diurnal discharge fluctuations due to evapotranspira- & - V-shaped, rapidly downcutting valley \\
& tion & \\
\hline WS03 & - Highly dissected landscape & - Scoured to bedrock in 1996 leaving only small colluvial \\
& - Focused lateral inflows & deposits \\
& - Diurnal discharge fluctuations due to evapotranspira- & - Highly constrained, low colluvium analogue to WS01 \\
& tion & - V-shaped, rapidly downcutting valley \\
\hline Unnamed cr. & - Surficial aquifer on earthflow connects several parallel & - Deep-seated earthflow \\
& channels & - No defined valley; parallel stream channels down hills- \\
& - Minimal lateral tributary area & lope \\
\hline Cold Cr. & - Extensive aquifer provides high discharge, cold base- & - Compressed glacial tills \\
& flow year-round & - U-shaped valley (glacial cirque) \\
& - Diffuse lateral inflows & - Uniform lateral tributary area \\
\hline
\end{tabular}

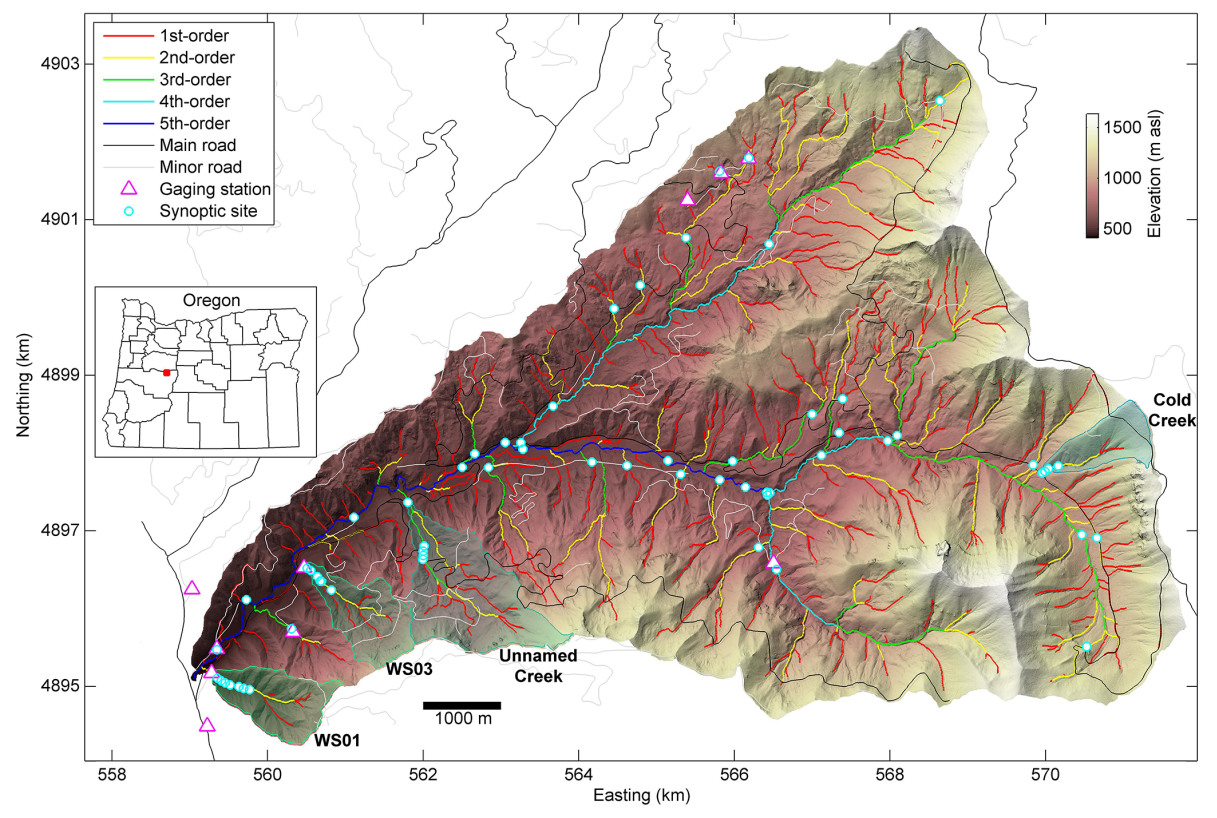

Figure 1. Synoptic study sites and lidar-derived stream network for the H. J. Andrews Experimental Forest. Reprinted with permission from Ward et al. (2019).

trast to the highly dissected landforms in WS01 and WS03). Bedrock is rarely visible along the study site. We selected a 2nd-order reach of Cold Creek to represent this landform (Fig. 1).

\subsubsection{Synoptic study}

We conducted a synoptic study at 46 sites within the HJA during late summer baseflow conditions (Fig. 1) that included solute tracer experiments. Site selection was stratified by stream order so that more headwater sites were sam- pled than higher-order reaches, as suggested by other synoptic investigations of sediment-water interfaces at the basin scale (Ruhala et al., 2017; Lee-Cullin et al., 2018). We selected low-baseflow conditions to maximize our ability to measure $Q_{\mathrm{HEF}} / Q$, which is expected to be largest under lowdischarge conditions (Wondzell, 2011). Study sites were selected to achieve coverage across stream orders, landforms, and on the basis of accessibility from roads in the basin. The data described here are documented and field methods de- 
scribed in detail by Ward et al. (2019), but we provide an overview below.

At each site we measured mean stream width and depth, valley width, and collected GPS coordinates. Subsequently, a modified version of TopoToolbox 2.0 (Schwanghart and Kuhn, 2010; Schwanghart and Scherler, 2014) and a $1 \mathrm{~m}$ lidar-derived, digital elevation model (DEM) was used to extract upslope accumulated area (UAA, ha), valley slope $\left(S_{\mathrm{val}}, \mathrm{m} \mathrm{m}^{-1}\right)$, and a stream centerline that was used to calculate sinuosity (sinuosity, $\mathrm{m} \mathrm{m}^{-1}$ ). Our methods were identical to those previously used in the basin (Corson-Rikert et al., 2016; Schmadel et al., 2017; Ward et al., 2018a, c).

At each synoptic site, we drove a Solinst $615 \mathrm{~N}$ well point into the streambed so that the top of the $0.15 \mathrm{~m}$ screened interval was $50 \mathrm{~cm}$ below the streambed. After developing the well with a peristaltic pump, we conducted three to six replicate falling head tests, measuring head change through time using a down-well Van Essen Micro-Diver logging at $0.5 \mathrm{~s}$ intervals. Falling head tests were interpreted using the Hvorslev (1951) method:

$$
K=\frac{r^{2} \ln \left(\frac{L_{e}}{R}\right)}{2 L_{e} T_{0}},
$$

where $K$ is hydraulic conductivity $\left(\mathrm{m} \mathrm{s}^{-1}\right), r$ is the radius of the well casing $(0.025 \mathrm{~m}), R$ is the radius of the well screen $(0.005 \mathrm{~m}), L_{e}$ is the screened length of the well (m), and $T_{0}$ is the time for the head to fall to about $37 \%$ of its original value (i.e., the $e$-folding time, s). We took the geometric mean of the replicate tests as the representative value of $K$ at each site.

We calculated the capacity of the subsurface to convey water down the valley bottom ( $Q_{\text {sub,cap }}$, sometimes termed "underflow", $\mathrm{m}^{3} \mathrm{~s}^{-1}$ ) as

$Q_{\text {sub,cap }}=b_{\text {valley }} h_{\text {valley }} K S_{\text {val }}$

following Ward et al. (2018a), where $b_{\text {valley }}$ is the valley width, $h_{\text {valley }}$ is the valley colluvium depth (m, estimated as $50 \%$ of the wetted channel width). This estimate is consistent with depths used in past studies (Gooseff et al., 2006; Ward et al., 2012, 2018a, c; Crook et al., 2008; Schmadel et al., 2017) and geophysical transects in the 4th- and 5th-order reaches of Lookout Creek (Steven M. Wondzell, unpublished data). We calculated hyporheic potential (HYP $\mathrm{POT}_{\mathrm{PO}}, \mathrm{m} \mathrm{s}^{-1}$ ) after Wondzell (2011), a similar metric that does not account for valley width, depth, or porosity, as

$\mathrm{HYP}_{\mathrm{POT}}=S_{\mathrm{val}} K$.

We also calculated stream power $\left(\Omega, \mathrm{W} \mathrm{m}^{-2}\right)$ at each tracer release location as

$\Omega=\rho g Q S$,

where $\rho$ is the density of water $\left(\mathrm{kg} \mathrm{m}^{-3}\right), g$ is the gravitational constant $\left(9.81 \mathrm{~m} \mathrm{~s}^{-2}\right), Q$ is the average discharge in the study segment $\left(\mathrm{m}^{3} \mathrm{~s}^{-1}\right)$, and $S$ is the DEM-derived slope along the stream channel in the study segment $\left(\mathrm{m} \mathrm{m}^{-1}\right)$.

Finally, at each site, we established a stream-tracer study reach with length approximately 20 times the wetted channel width that would be representative of reach-scale morphologic variation (MacDonald et al., 1991; Montgomery and Buffington, 1997; Rot et al., 2000; Martin, 2001; Anderson et al., 2005). We instantaneously released a known mass of $\mathrm{NaCl}$ (assumed conservative), dissolved in stream water, one mixing length (i.e., the distance required for the solute tracer to be well-mixed across the channel cross section) from the downstream end of the study reach, where we monitored in-stream specific conductance (Onset Computer Corporation, Bourne, MA, USA). Mixing lengths were based on visual estimates in the field as empirical estimates are unreliable in mountain streams (Day et al., 1977). Moreover, field experience in a study system is recognized to be potentially more useful than theoretical estimates of mixing length (Kilbatrick and Cobb, 1985). Thus, we used visual estimates that are consistent with our past studies using these techniques and tracers in H. J. Andrews Experimental Forest (Ward et al., 2012, 2013a, b; 2019; Voltz et al., 2013) and practices used in other mountain stream networks (e.g., Payn et al., 2009; Covino et al., 2010). Next, we released a second known mass of $\mathrm{NaCl}$ one mixing length above the upstream end of the study reach. We monitored in-stream specific conductance at both the up- and downstream ends of the study reach. Mixing lengths were visually estimated in the field; small amounts of a fluorescent dye were used to assess mixing lengths where they could not be readily determined by surface hydraulic conditions. All in-stream specific conductance measurements were converted to concentrations of $\mathrm{NaCl}$ mass added using a four-point calibration curve developed from standards made by mixing varying amounts of $\mathrm{NaCl}$ with stream water that encompassed the range of observations during the tracer tests. Results from all sensors were composited into a single linear regression $\left(r^{2}>0.99\right)$.

\subsubsection{Fixed-reach studies}

We established 11 fixed reaches of about $50 \mathrm{~m}$ of valley length in the four headwater catchments. We conducted identical site characterizations as described above for the synoptic study. However, for each study reach, solute tracer injections were conducted two to six times through baseflow recession. The differing number of replicates reflects either sensor failure or omission of a replicate due to conflicting research occurring at the same sites by other researchers (i.e., our replication would have negatively impacted their independent research campaigns, so we did not proceed with our injections). These sites parallel the common approach of replication of a study at a fixed reach with varied discharge to relate river corridor exchange to discharge conditions (after Payn et al., 2009). 


\subsubsection{Reach length and study design}

In the synoptic campaign, we scaled our tracer reach lengths by wetted channel width in an effort to control for the advective timescales of the study. To demonstrate how this decision, or conversely the decision to fix our study reach in headwaters, may have biased our data collected, we conducted a series of four tracer injections in the 1st through 4th stream orders in the study basin. For each study we fixed a single location for the injection and placed sensors downstream at three distances: (1) a fixed reach of $150 \mathrm{~m}$; (2) an estimated 10 min of advective time downstream, based on timing debris floating along approximately $5 \mathrm{~m}$ of stream; and (3) a distance of 20 times the wetted channel width, which was identified as a length scale for a representative study reach in the HJA (Anderson et al., 2005; Gooseff et al., 2006). All injection protocols were consistent with synoptic and replicate injections described above.

\subsection{Analysis of stream solute tracer injections}

There is no single, widely agreed upon, robust framework for describing river corridor exchange based on stream solute tracer experiments. Instead, a host of approaches have been successfully used to interpret experimental data. In this section we detail the interpretation of stream solute tracers using several established approaches. Notably, the interpretations here were selected because they most directly interpret the observed solute tracer time series, in contrast to other strategies that focus on inverse model parameterization (e.g., Bencala and Walters, 1983; Haggerty and Reeves, 2002) and may be prone to parameter uncertainty and identifiability challenges (e.g., Ward et al., 2017a; Kelleher et al., 2013; Rana et al., 2019). The suite of approaches implemented here was selected because they provide complementary interpretations that may be informative when jointly considered (Table 2). We emphasize here that we do not seek a singular, "best" metric to describe river corridor exchange, but instead we seek to interpret a suite of metrics to provide a comprehensive understanding of our study system.

\subsubsection{Separation of advection-dispersion from transient storage}

We separated the recovered solute tracer mass into fractions that were primarily related to advection-dispersion and to short-term transient storage (after Wlostowski et al., 2017). Briefly, stream velocity $\left(v, \mathrm{~m} \mathrm{~s}^{-1}\right)$ is estimated as $v=L / t_{\text {peak }}$, where $L$ is the length of the reach along the centerline, and $t_{\text {peak }}$ is the time at which the peak breakthrough curve concentration is observed, interpreted as the advective timescale of the study reach. The stream cross-sectional area $\left(A, \mathrm{~m}^{2}\right)$ is estimated by $A=Q_{\mathrm{DS}} / v$, where $Q_{\mathrm{DS}}$ is an estimate of discharge at the downstream end of the study reach based on dilution gauging. The mass of solute tracer recov- ered from the upstream injection at the downstream end of the study reach $\left(M_{\mathrm{REC}}, \mathrm{g}\right)$ is calculated as

$M_{\mathrm{REC}}=Q_{\mathrm{DS}} \int_{0}^{t_{99}} C_{\mathrm{obs}}(t) \mathrm{d} t$,

where $C_{\text {obs }}\left(\mathrm{g} \mathrm{m}^{-3}\right)$ is the observed solute tracer concentration at the downstream location in response to the upstream solute tracer injection. Using these estimates, the analytical solution to the advection-dispersion equation given the instantaneous tracer addition method is

$C_{\mathrm{ADE}}(t)=\frac{M_{\mathrm{REC}}}{A(4 \pi \mathrm{D} t)^{1 / 2}} \exp \left[\frac{(L-v t)^{2}}{4 D t}\right]$,

where $C_{\mathrm{ADE}}\left(\mathrm{g} \mathrm{m}^{-3}\right)$ is the concentration time series predicted for the recovered mass transported via advection and dispersion only, $M_{\text {REC }}$ is mass recovered (g), and $D$ is the best-fit longitudinal dispersion coefficient $\left(\mathrm{m}^{2} \mathrm{~s}^{-1}\right)$. Following this approach, the concentration time series for a solute that is predominantly transported by advection and dispersion $\left(C_{\mathrm{AD}}\right)$ can be estimated as

$C_{\mathrm{AD}}(t)=\left\{\begin{array}{l}C_{\mathrm{obs}}(t) ; C_{\mathrm{ADE}}(t)>C_{\mathrm{obs}}(t) \\ C_{\mathrm{ADE}}(t) ; C_{\mathrm{ADE}}(t)<C_{\mathrm{obs}}(t)\end{array}\right.$.

The total mass associated with advection and dispersion $\left(M_{\mathrm{AD}}\right)$ can be calculated as

$M_{\mathrm{AD}}=\int_{0}^{t_{99}} C_{\mathrm{AD}}(t) Q_{\mathrm{DS}} \mathrm{d} t$,

where $t_{99}(\mathrm{~s})$ is the time at which $99 \%$ of the recovered tracer signal has passed by the monitoring location. The component of $C_{\mathrm{obs}}$ that is primarily impacted by transient storage $\left(C_{\mathrm{TS}}\right.$, $\mathrm{g} \mathrm{m}^{-3}$ ) can be calculated as

$C_{\mathrm{TS}}=C_{\mathrm{obs}}-C_{\mathrm{AD}}$.

Similar to $M_{\mathrm{AD}}$, the mass associated with transient storage $\left(M_{\mathrm{TS}}, \mathrm{g}\right)$ can be calculated as

$M_{\mathrm{TS}}=\int_{0}^{t_{99}} C_{\mathrm{TS}}(t) Q_{\mathrm{DS}} \mathrm{d} t$.

Finally, we calculate the fraction of recovered mass primarily involved in advection-dispersion $\left(f_{\mathrm{MAD}}\right)$ or transient storage $\left(f_{\text {MTS }}\right)$ as

$f_{\mathrm{MAD}}=\frac{M_{\mathrm{AD}}}{M_{\mathrm{REC}}}$

and

$f_{\mathrm{MTS}}=\frac{M_{\mathrm{TS}}}{M_{\mathrm{REC}}}$. 


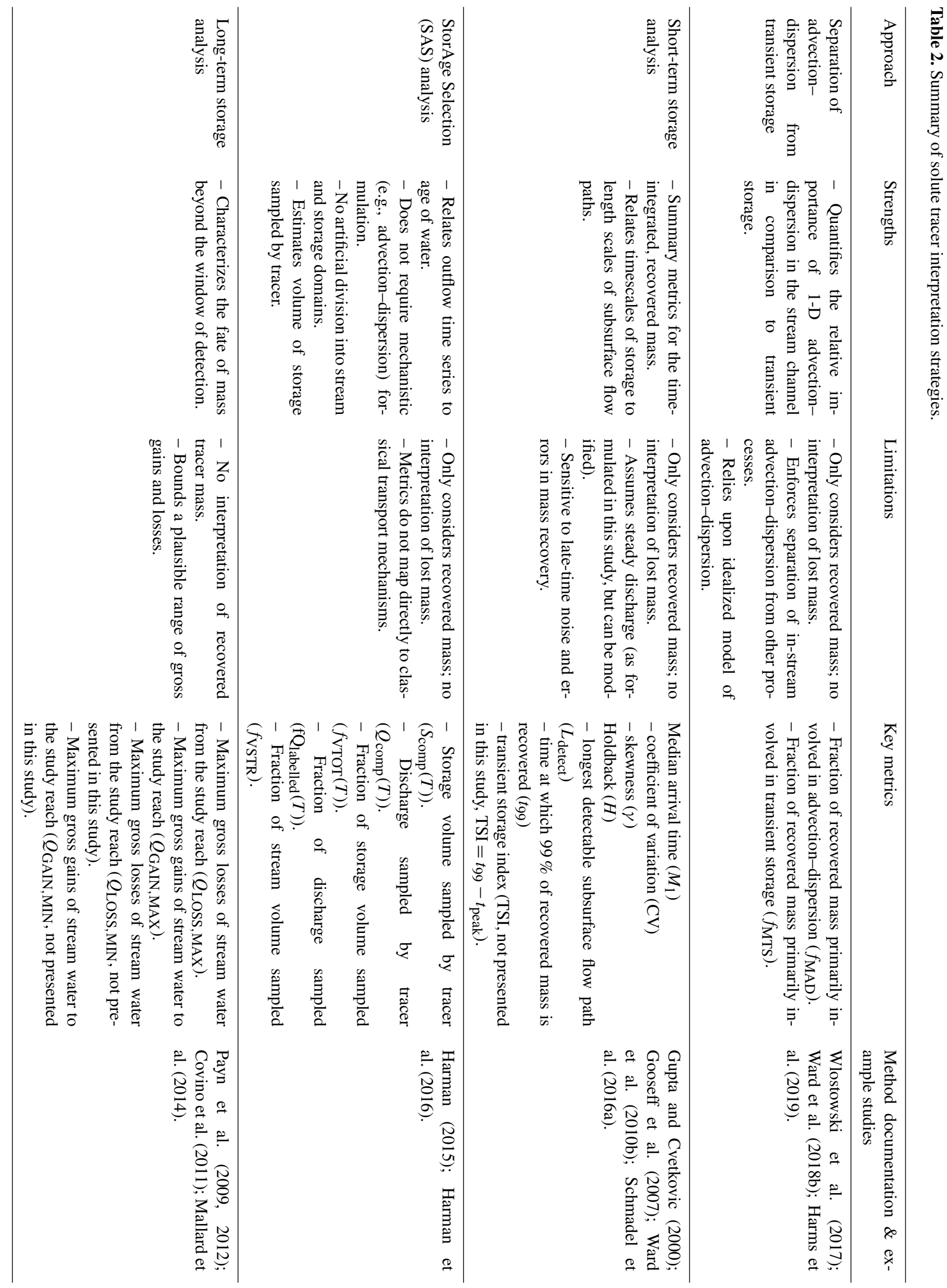




\subsubsection{Short-term storage analysis}

Observations of stream solute tracer releases were analyzed using a host of time series metrics. We calculated the time at which $99 \%$ of the total mass recovery was achieved ( $t_{99}$, s). To minimize the impacts of late-time noise on calculated metrics, $C_{\text {obs }}$ was truncated at the downstream end to only include times bounded by the injection time and $t_{99}$ (hereafter $C_{\text {obs }}(t)$ ), consistent with common practices (e.g., Mason et al., 2012; Ward et al., 2013a, b; Schmadel et al., 2016a) and a community tool for interpretation of solute tracers (Ward et al., 2017a). The truncated time series was normalized to isolate the features of the data in the temporal domain and minimize effects of different concentration magnitudes between injections. The normalized breakthrough curve $(c(t))$ was calculated as

$c(t)=\frac{C_{\mathrm{obs}}(t)}{\int_{t=0}^{t_{99}} C_{\mathrm{obs}}(t) \mathrm{d} t}$.

We calculated the median arrival time $\left(M_{1}\right.$, equivalent to the first temporal moment, s) as

$$
M_{1}=\int_{t=0}^{t_{99}} t c(t) \mathrm{d} t
$$

Next, we calculated the 2nd- and 3rd-order moments about $M_{1}\left(\mu_{2}\right.$ and $\left.\mu_{3}\right)$ as

$\mu_{n}=\int_{t=0}^{t_{99}}\left(t-M_{1}\right)^{n} c(t) \mathrm{d} t$,

where $n$ represents the $n$ th-order moment, and $\mu_{2}$ and $\mu_{3}$ contain information about symmetrical and asymmetrical spreading of the time series, respectively. The central moments were normalized to provide information that could be compared between sites and injections by calculating the coefficient of variation $(\mathrm{CV})$ and skewness $(\gamma)$ as

$$
\begin{aligned}
& \mathrm{CV}=\frac{\mu_{2}^{1 / 2}}{M_{1}}, \\
& \gamma=\frac{\mu_{3}}{\mu_{2}^{3 / 2}} .
\end{aligned}
$$

Finally, we calculated the holdback of the system $(H)$, which describes transport in a continuum ranging from piston flow $(H=0)$ to no movement of the solute $(H=1)$ (Danckwerts, 1953). Ward et al. (2018b) interpret higher values of $H$ to indicate greater influence of transient storage on reach-scale transport. Holdback is calculated as

$$
H=\frac{1}{M_{1}} \int_{t=0}^{M_{1}} F(t) \mathrm{d} t,
$$

where

$$
F(t)=\int_{\tau=0}^{t} c(\tau) \mathrm{d} \tau .
$$

Finally, we estimated the maximum detectable flow path length $\left(L_{\text {detect }}\right)$ as

$L_{\text {detect }}=t_{99} \frac{K}{\theta} S_{\mathrm{val}}$,

which is based on Darcy's law but uses the valley slope $\left(S_{\mathrm{val}}\right)$ as an estimate of the hydraulic gradient (after Wondzell, 2011; Ward et al., 2017b) and where $\theta$ is porosity.

\subsubsection{StorAge Selection (SAS) analysis}

We interpreted the transport of tracer through the study reach using the StorAge Selection (SAS) approach (Harman, 2015; Harman et al., 2016). Briefly, this approach can be used to describe the composition of outflowing water from a study reach as a combination of water sampled from different ages within the study reach. The approach is closely related to transit time distributions, but it isolates the contribution to the transit time of storage turnover from that of inflow and outflow variability. Although physically based, in the sense of conforming to conservation of mass and describing physically meaningful properties, this approach describes the higher-level emergent effects of mechanisms like advection, dispersion, and other processes (Harman et al., 2016). Instead, the approach provides a description of the reach as a zero-dimensional, integrated control volume (i.e., no arbitrary division of surface vs. subsurface or mobile vs. less mobile storage).

Here, we closely follow the adaptation of the general formulation of the SAS framework to interpret stream solute tracer results (Harman et al., 2016). Notably, we are able to further simplify the approach by assuming discharge was at steady state during each injection and having only a single release of tracer that did not overlap with other tracer signals. Under the assumption of steady flow, the forward and backward transit time distributions are equal. First, we calculated the probability density of the (forward) transit time distribution $\left(p_{Q}(T)\right)$ as

$p_{Q}(T)=\frac{Q C_{\mathrm{obs}}}{M_{\mathrm{US}}}$,

where $M_{\mathrm{US}}$ is the mass of the upstream tracer injection $(\mathrm{g})$. Note that, due to the steady-state assumption, $p_{Q}(T)$ is only a function of water age $T$ and does not depend on time $t$. Next, we calculated the cumulative form of the transit time distribution $\left(P_{Q}(T)\right)$ as

$P_{Q}(T)=\int_{\tau=0}^{T} p_{Q}(\tau) \mathrm{d} \tau$, 
where $\tau$ is a random variable representing the age of a parcel of water (Harman, 2015). This allows us to determine the age-ranked discharge $\left(Q_{T}(T)\right)$,

$Q_{T}(T)=Q P_{Q}(T)$,

and the age-ranked storage $\left(S_{T}(T)\right)$ as

$S_{T}(T)=Q\left(T-\int_{\tau=0}^{T} P_{Q}(\tau) \mathrm{d} \tau\right)$.

The age-ranked storage can be interpreted to determine the volume of reach storage that was sensed by the tracer. If the total storage in the study reach can be estimated, the fraction of total storage that was sensed by the tracer can also be determined. A perfect tracer study would be sensitive to the entirety of the storage volume. However, due to limitations arising from the window of detection and truncation of the breakthrough curve, only a fraction of the storage is actually measured (e.g., Drummond et al., 2012). The knowledge of measured volume is important and is one advance enabled by using this interpretation framework.

Plotting the age-ranked discharge as a function of the corresponding age-ranked storage reveals the SAS function (Harman 2015; Harman et al., 2016). This relationship shows how discharge is composed of water drawn from storage of different ages. Flipping this plot along each axis to plot the complements is advantageous to interpret the results (Harman et al., 2016). Thus, we plot the age-ranked discharge complement

$Q_{\text {comp }}(T)=Q\left(1-P_{Q}(T)\right)$

as a function of the age-ranked storage complement

$S_{\text {comp }}(T)=S_{\text {ref }}-S_{T}(T)$,

where $S_{\text {ref }}$ is the total storage in the study reach $\left(\mathrm{m}^{3}\right)$. We estimated $S_{\text {ref }}$ as the volume of the surface water (mean width $\times$ mean depth $\times$ length along centerline) plus the subsurface storage volume (valley width $\times$ valley segment length $\times$ depth $\times$ porosity). We estimated porosity as $30 \%$ for all locations (after Domenico and Schwartz, 1990; Ward et al., 2018a).

The SAS analysis can be interpreted to yield an understanding of how storage and discharge are related for the study. The minimum value of the age-ranked discharge complement ( $y$ axis of Fig. 2) gives the discharge of outflowing water in the channel that was not labeled by the tracer at the upstream end of the study reach within the window of detection. In practice, unlabeled discharge represents some combination of (1) down-valley flow entering the segment from upstream and then upwelling and (2) discharge originating from parts of storage that retain tracer for very long periods of time. Finally, while both the discharge and volume sampled will scale through the network, each can be normalized

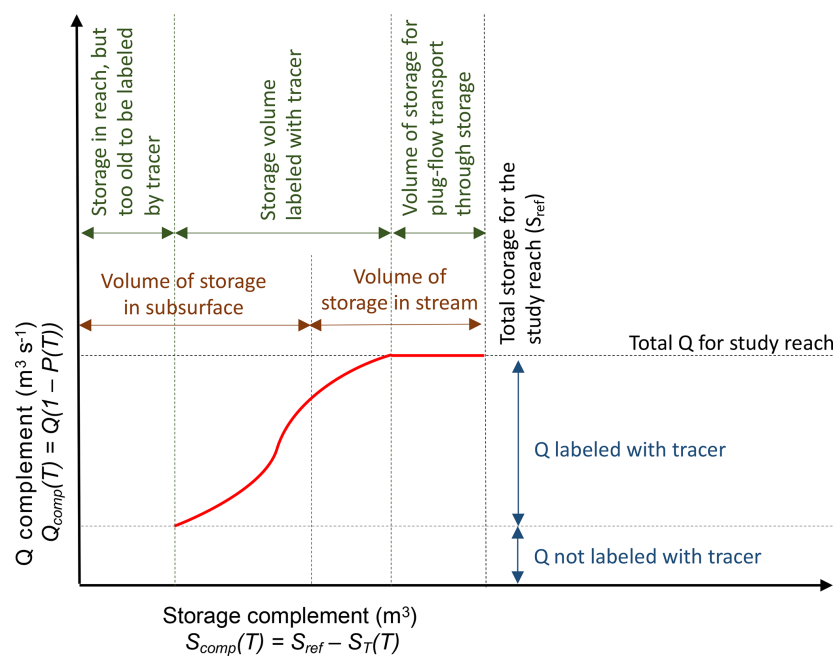

Figure 2. Graphical representation and interpretation the SAS function. Note that the volume of storage in the stream vs. subsurface (orange above) is independent of the SAS analysis and is provided here as an example of integrating the SAS metrics with other knowledge about the system.

to a reference value as

$f_{\mathrm{VTOT}}(T)=\frac{S_{\text {comp }}(T)}{S_{\text {ref }}}$,
$f_{Q, \text { labeled }}(T)=\frac{Q_{\text {comp }}(T)}{Q+Q_{\text {sub }, \text { cap }}}$,

where $f_{\mathrm{VTOT}}$ is the fraction of the total storage volume that was sampled with the tracer, and $f_{Q \text {,labeled }}$ is the fraction of the total down-valley discharge that was labeled with the tracer. We also calculated the fraction of the in-stream volume sampled ( $\left.f_{\text {VSTR }}\right)$ as

$f_{\mathrm{VSTR}}=\frac{S_{\mathrm{comp}}(T)}{A L}$.

The SAS approach requires a physically plausible bounding by input values. In practice, this means that errors in discharge can cause overestimations of mass recovery (i.e., greater than the mass that was injected), leading to physically impossible $Q_{T}(T)$ values. As a result, we assumed a typical error of $10 \%$ for dilution gauging (Schmadel et al., 2010). Within that range of discharge values, we calculated the range of physically plausible discharges (i.e., those which yield physically meaningful SAS calculations) and analyzed the midpoint of the plausible range. In the first study using the SAS approach to interpret solute tracers, Harman et al. (2016) found that a similar discharge adjustment was required to define the feasible parameter space.

\subsubsection{Long-term storage analysis}

Long-term storage characterized the fate of mass beyond the window of detection (i.e., unrecovered mass that did not contribute to the analysis of short-term storage; Payn et al., 2009; 
Ward et al., 2013c). Dilution gauging at the up- and downstream ends of each study reach was used to estimate discharge ( $Q_{\mathrm{US}}$ and $Q_{\mathrm{DS}}$, respectively, $\mathrm{m}^{3} \mathrm{~s}^{-1}$ ). Mass loss along the study reach can be calculated by the difference of the mass injected $\left(M_{\mathrm{US}}, \mathrm{g}\right)$ and $M_{\mathrm{REC}}$ :

$$
M_{\mathrm{LOSS}}=M_{\mathrm{US}}-M_{\mathrm{REC}} .
$$

Finally, Payn et al. (2009) demonstrate how $M_{\text {LOSS }}, Q_{\mathrm{US}}$, and $Q_{\mathrm{DS}}$ can be used to bound the gross gains and losses of water to the channel through the study reach. We focus here on the case of all losses occurring before all gains, which is the end-member that yields the largest estimates for gross losses $\left(Q_{\mathrm{LOSS}, \mathrm{MAX}}\right)$ and gains $\left(Q_{\mathrm{GAIN}, \mathrm{MAX}}\right)$, respectively, calculated as

$$
\begin{aligned}
Q_{\mathrm{LOSS}, \mathrm{MAX}} & =\frac{M_{\mathrm{LOSS}}}{\int_{0}^{t_{99}} C_{\mathrm{obs}, \mathrm{d} s}(t) \mathrm{d} t}, \\
Q_{\mathrm{GAIN}, \mathrm{MAX}} & =Q_{\mathrm{DS}}-Q_{\mathrm{US}}-Q_{\mathrm{LOSS}, \text { MAX }} .
\end{aligned}
$$

The net change in discharge along the study reach $(\Delta Q)$ is represented by the terms $Q_{\mathrm{DS}}-Q_{\mathrm{US}}$ in the equation above. To compare between reaches, we normalized $M_{\text {LOSS }}$ by $M_{\text {INJ }}$ and normalized the gross gains and losses by $Q_{\text {US }}$. We also calculate gross gains and gross losses, $f_{\mathrm{QGAIN}, \mathrm{MAX}}$ and $f_{\text {QLOSS,MAX }}$, as a fraction of the inflow at the upstream end of the reach.

\subsection{Statistical tests}

We applied a Mann-Kendall (MK) test to examine relationships between the metrics of river corridor exchange and characteristics of geologic setting and hydrologic forcing. The MK test is a nonparametric test used to assess the likelihood of a monotonically increasing or decreasing trend in a dataset, which we interpret as the presence of a systematic trend through the river network. The MK test only provides an indication of a relationship's existence and does not characterize the direction or magnitude of the relationship. Thus, we also calculated Sen's slope, a nonparametric test to fit a robust linear slope to a dataset by choosing the median of slopes connecting all potential pairs of points. This metric was selected because it is less sensitive to outliers than a traditional linear regression and more robust for skewed or heteroscedastic data. Thus, we use the MK test to define the presence or absence of a statistically significant trend $(p<0.05)$ and Sen's slope to indicate the direction of that trend (positive or negative). We also compare the magnitude of Sen's slope among and within datasets to estimate the relative sensitivity of selected dependent variables to the same independent variable.

For the synoptic data we also report the coefficient of determination $\left(r^{2}\right)$ for univariate best-fit power-law regression as an indicator of the predictive power of a parsimonious model fit. The coefficient of determination is commonly interpreted as the percent of variance explained by the model.
We selected a power-law regression because most independent and dependent variables span orders of magnitude. We did not test other functional forms as the purpose of this fit is to assess the explanatory power of a simple regression model - comparable to those commonly used to interpret field data for identifying relationships between two variables - rather than identify an optimal predictive equation that relates the two variables. Finally, we fit a planar surface to each metric as a function of log-transformed baseflow and $\mathrm{HYP}_{\mathrm{POT}}$ to approximate the conceptual model proposed by Wondzell (2011). We selected a planar surface in log space as the simplest representation of a relationship. We also fit univariate linear relationships to the log-transformed $Q$ and НYР РОт data for each metric. We emphasize here that our focus was on attesting the conceptual model of Wondzell (2011), not an exhaustive curve- or surface-fitting exercise.

\section{Results}

\subsection{Spatial patterns in hydrologic and geomorphic controls}

Overall, all landscape metrics exhibited statistically significant monotonic trends with one another (MK test, $p<0.05$ ). We found expected trends of increasing UAA (Fig. 3a) velocity (Fig. 3b) and stream order (Fig. 3c) with discharge. We also found an increasing hydraulic conductivity in the down-network direction (Fig. 3d), which is indicative of sediment size and sorting in high-relief headwater landscapes (Brummer and Montgomery, 2003), but opposite to typical low-relief alluvial systems (e.g., Gomez-Velez et al., 2015). Moving from the headwaters to the outlet, we found flattening and widening of the valley with increasing discharge and UAA along the network (Fig. 3e, f), increasing stream power (Fig. 3g), and increasing sinuosity (Fig. 3i). This trend reflects the prevalence of fine material in the upper reaches emplaced by debris flows and coarsening in the downstream direction where stream power increases, thus exporting fines from the system. The result of these trends in valley morphology and hydraulic conductivity is an increasing trend in $Q_{\text {sub,cap }}$ in lower network positions (Fig. 3h), indicating the increasing width and $K$ are sufficient to overcome the decreases in slope in generating this relationship. Pairwise Pearson correlation coefficients and Spearman rank correlation coefficients are summarized in Supplement Figs. S3 and S4 and Tables S1 and S2.

\subsection{River corridor exchange trends with site characteristics}

\subsubsection{Basin-scale trends from synoptic campaign}

An important element in our synoptic study design was the dynamic reach length, intended to minimize bias associ- 

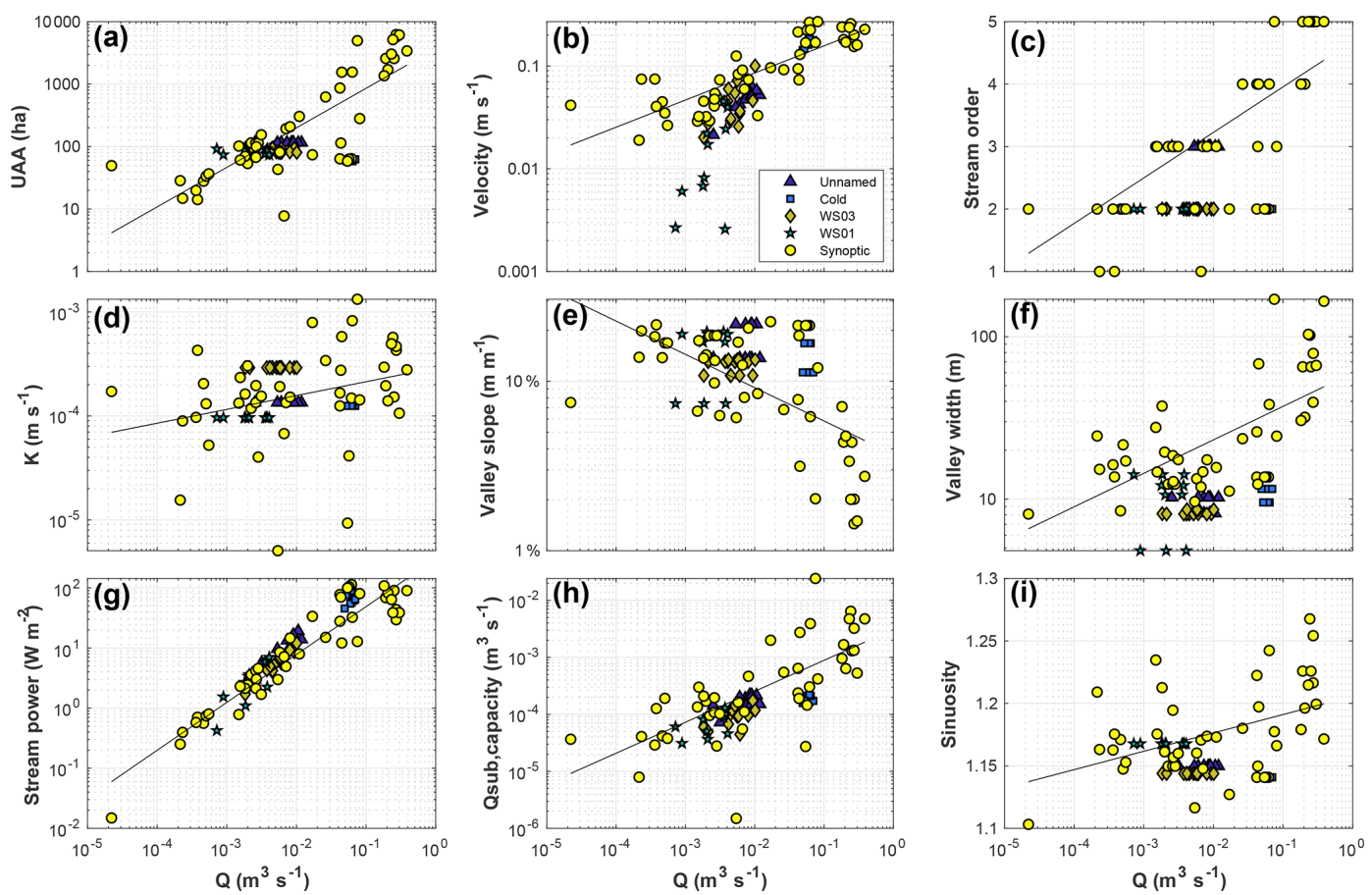

Figure 3. For synoptic data (yellow circles), discharge exhibits a significant, monotonic trend with all other site variables considered (MannKendall test, $p<0.05$ ). Pairwise MK test results for all site characteristic pairs (i.e., all $y$ axis variables presented above) exhibit significant trends for all combinations $(p<0.05)$. The solid black line shows the best-fit power-law regression for each panel. Data from unnamed creek (triangles, Cold creek (squares), WS03 (diamonds), and WS01 (stars) show the repeated injections through baseflow recession for each headwater catchment. See Supplement Figs. S1 and S2 for similar plots with HYP POT and UAA on the $x$ axis.

ated with the well-documented relationship between advective timescale and transient storage (e.g., Ward et al., 2013b; Schmadel et al., 2016a). Despite our efforts to hold advective travel time constant, we still found a trend of increasing $t_{\text {peak }}$ with increasing discharge in our synoptic study (Fig. 4a). Clearly, scaling reach length relative to the wetted channel width ( 20 wetted channel widths) is not a perfect solution. A perfect experimental design would have resulted in no trend in advective time and provided a window of detection of constant size. While a trend was present, we also note that travel time based on $t_{\text {peak }}$ exhibits less variation than discharge (coefficient of variation 1.00 for travel time compared to 1.49 for discharge). For context, a recent study by Ward et al. (2018b) attempted to control for experiments with $20 \mathrm{~min}$ of advective time and accepted a range from 17 to $50 \mathrm{~min}$ as comparable. Thus, while our selection of study reach lengths was imperfect to achieve identical advective timescales, we contend that we have adequately controlled for advective time.

Overall we found significant trends (MK test, $p<0.05$ ) between nearly all site characteristics and metrics describing river corridor exchange. Of the 130 pairings investigated, only three (stream order vs. $L_{\text {detect }}$, stream order vs. $f_{\mathrm{MAD}}$, sinuosity vs. $f_{Q}$, labeled) were not significant (Table 3 ). However, while network-scale trends do exist, we note high siteto-site variation in the dataset as evidenced by the low $r^{2}$ for the power-law fits (see trend lines in Fig. 4), representa- tive of the range of explanatory power observed. Across all 130 pairings investigated, we found very little explanatory value in the model fits, with a median $r^{2}$ of less than 0.03 (i.e., the variance in the model errors is about $3 \%$ less than the variance in the dependent variable itself). The lack of explanatory power for individual variables may indicate that fits based on more complex functional forms and/or multivariate approaches would increase predictive power. We did observe improved $r^{2}$ for all fits using both $Q$ and HYР РОт compared to univariate regressions (Table $\mathrm{S} 3$ ).

\subsubsection{Fixed-reach vs. synoptic results}

We found decreasing $t_{99}$ with increasing discharge for the synoptic study (Fig. 4d), which in turn resulted in a systematic reduction in the possible length of flow paths that could be detected by tracer (Fig. 4g). Note that this ranges, on average, from $0.35 \mathrm{~m}$ at the lowest discharge to only $0.09 \mathrm{~m}$ at the highest discharge, and the reach with the largest $L_{\text {detect }}$ was only $2.0 \mathrm{~m}$. In contrast, reach lengths used in the fixed-reach studies were much longer relative to stream size than the synoptic reaches; thus $t_{\text {peak }}, M_{1}, t_{99}$, and $L_{\text {detect }}$ were all much larger in the fixed-reach studies (Table 4). These metrics all exhibited significant trends with discharge (Table 3), but the trends were not regularly consistent in their direction with the synoptic results. Overall, we found predominantly decreas- 


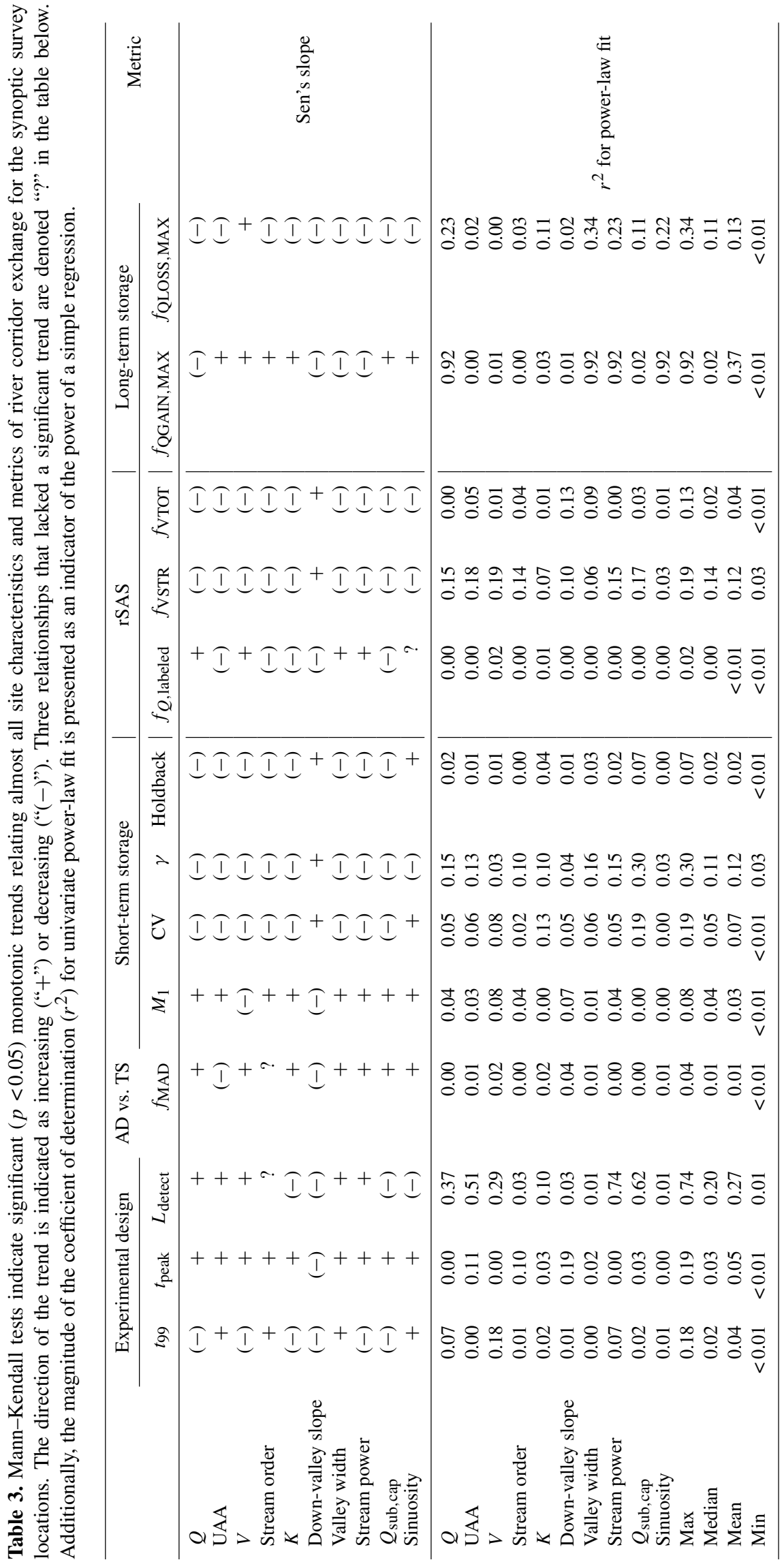



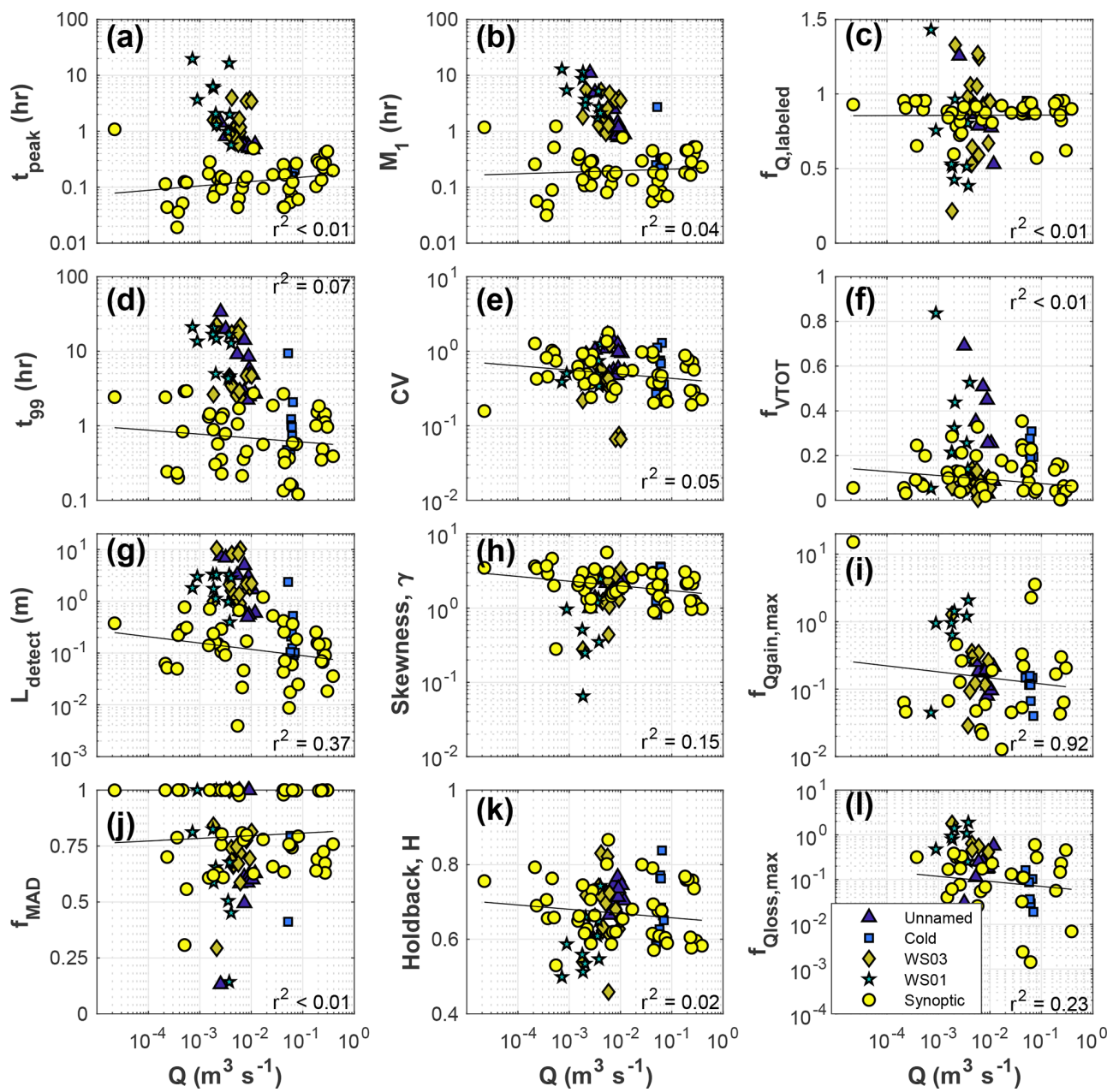

Figure 4. Fixed-reach and synoptic data as a function of stream discharge. Statistical likelihood of significant relationships (Mann-Kendall test) and their direction (Sen's slope) are detailed for all sub-reaches and the synoptic data in Table 3. All trends shown here are significant (MK test, $p<0.05$ ). The coefficients of determination for power-law best fits to synoptic data (black lines) are reported in Table 3. Data from unnamed creek (triangles, Cold creek (squares), WS03 (diamonds), and WS01 (stars) show the repeated injections through baseflow recession of each headwater catchment. See Supplement Figs. S5 and S6 for similar plots with HYPPOT and UAA on the $x$ axis.

ing $t_{\text {peak }}$ with discharge in the fixed reaches - opposite to the synoptic finding - for 9 of 11 fixed reaches (and steeper Sen's slope in 9 of 11 fixed reaches). We also found decreasing $t_{99}$ with discharge in 9 of 11 fixed reaches (all with steeper Sen's slope than the synoptic) and decreasing $L_{\text {detect }}$ with discharge in 9 of 11 fixed reaches (all with steeper Sen's slope than the synoptic). Even with the longer reach lengths, relative to stream size, used in the fixed-reach studies, $L_{\text {detect }}$ averaged only $\sim 2.0 \mathrm{~m}$ and ranged from a maximum of $10 \mathrm{~m}$ to a minimum of $0.10 \mathrm{~m}$.

With respect to short-term storage, we found increasing $M_{1}$ with increasing discharge in the synoptic study, but this direction was reflected in only 2 of 11 fixed reaches. Sen's slope was larger in magnitude for 10 of the 11 fixed reaches, indicating $M_{1}$ interpreted from the fixed-reach approach is more sensitive to discharge than the synoptic approach. We found overall decreasing $\mathrm{CV}, \gamma$, and $H$ with increasing dis- charge in the synoptic study, indicating a decreasing importance of non-advective processes in the downstream direction along the network. The direction of this trend is consistent with seven fixed reaches for CV, two sites for $\gamma$, and three sites for $H$. Regardless of the direction of the relationship, the magnitude of Sen's slope was larger for all fixed reaches compared to the synoptic study, indicating increased sensitivity to discharge relative to the synoptic sites.

For long-term storage and mass involved in advectiondispersion, we again found fixed-reach trends were steeper and often opposed the direction of the trend for the synoptic data. For the synoptic study we found decreasing $f_{\text {Qgainmax }}$ (Fig. 4i) and $f_{\text {Qloss, max }}$ (Fig. 4l) with increasing discharge, which is consistent with five and six of the 11 fixed reaches, respectively. For the synoptic study we found an overall decreasing $f_{\mathrm{MAD}}$ with increasing discharge, consistent with seven of the 11 fixed reaches. The magnitude of Sen's slope 


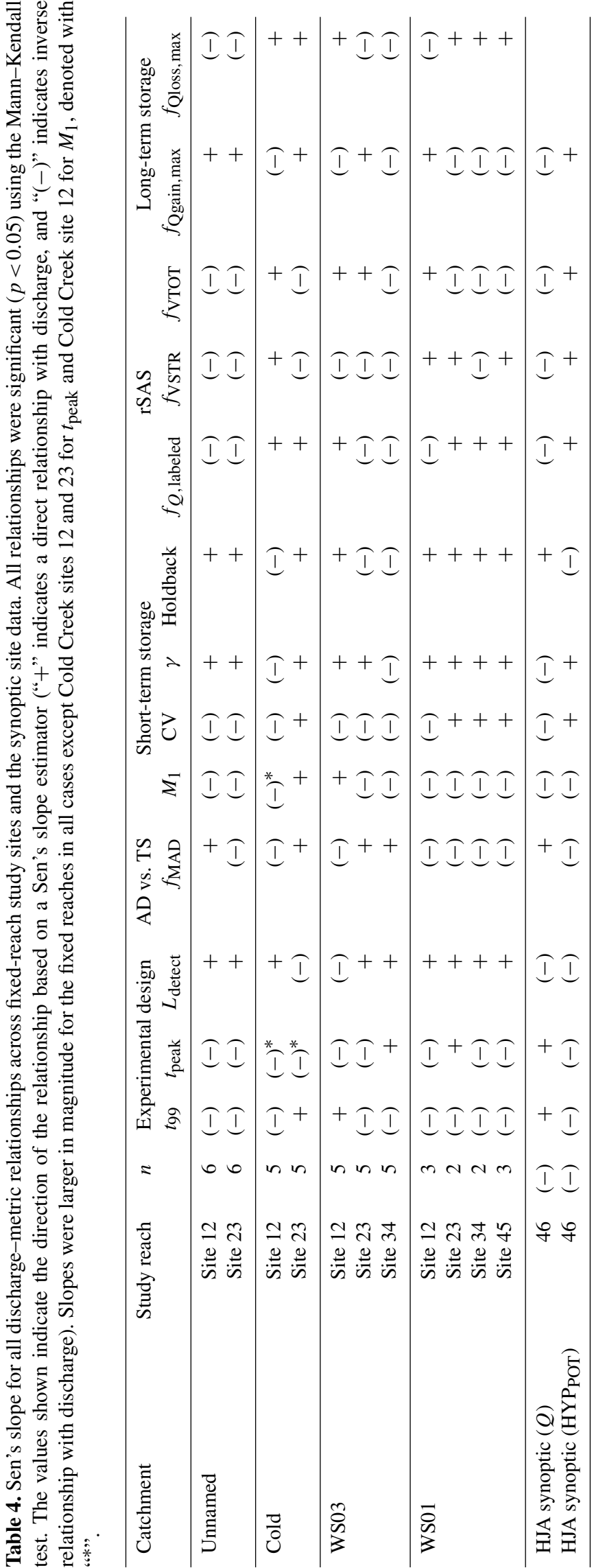

was larger for the fixed reaches than the synoptic study for $f_{\text {MAD }}, f_{\text {Qgainmax }}$, and $f_{\text {Qlossmax. }}$.

The SAS analysis revealed decreasing sampling of the total storage zone $\left(f_{\mathrm{Vtot}}\right)$ with increasing discharge but increasing $f_{Q \text {,labeled }}$ with discharge for the synoptic study. Together, these results indicate that increasing discharge in synoptic experiments resulted in sampling a larger fraction of the water exiting the reach but smaller total volume of storage. Put another way, experiments in locations with higher discharge were more likely to measure storage in (or proximal to) the stream channel at the expense of measuring more distal flow paths and less-connected storage. For the fixed-reach studies, we found decreasing $f_{\mathrm{Vtot}}$ and $f_{Q \text {,labeled }}$ in seven and six of the 11 reaches, respectively. In all cases, the magnitude of Sen's slope was larger for the fixed reaches than the synoptic study.

\subsection{Selection of study reach length across the network}

For the injections that specifically tested the study reach length, we found the most consistent advective timescales were obtained by scaling reach length to 20 times wetted channel width (Fig. 5). Ranges of advective timescales were $25.2 \mathrm{~min}$ for the fixed-length approach, $27.2 \mathrm{~min}$ for the fixed-timescale approach, and $4.8 \mathrm{~min}$ for the $20 \times$ wetted channel width approach (Fig. 5a). It is notable that our estimates of a $10 \mathrm{~min}$ advective time were reasonably accurate for the three highest-discharge reaches, but the lowestdischarge replicate primarily drives the visually steep trend. We hypothesize that a better estimate of advective velocity such as using a dye tracer rather than following debris or a longer length scale of integration - may have improved that estimate. For $t_{99}$, ranges for the $10 \mathrm{~min}$ and $150 \mathrm{~m}$ approaches are about $29 \%$ and $22 \%$ larger, respectively, than the $20 \times$ wetted channel width approach (Fig. 5b). Differences are even more striking for other parameters, with the $10 \mathrm{~min}$ and $150 \mathrm{~m}$ study designs yielding $147 \%$ and $93 \%$ larger ranges for $H$ compared to the $20 \times$ wetted channel width approach (Fig. 5c). Similarly, the $10 \mathrm{~min}$ and $150 \mathrm{~m}$ approaches result in ranges of $\gamma$ that are $96 \%$ and $101 \%$ larger than the ranges using the $20 \times$ wetted channel width approach (Fig. 5d).

\section{Discussion}

\subsection{How do discharge and local geomorphic setting modulate river corridor exchange?}

Our overarching objective in this study was to test the conceptual model of Wondzell (2011), which predicted systematic changes in river corridor exchange as a function of changing baseflow and geomorphic setting (Fig. 6a). We found a generally decreasing influence of river corridor exchange with increasing steady-state discharge through space for most metrics considered (Figs. 4, 6b-f). While we could not measure exchange flux directly, we find $t_{99}, f_{\mathrm{MTS}}, f_{\mathrm{VTOT}}$, 

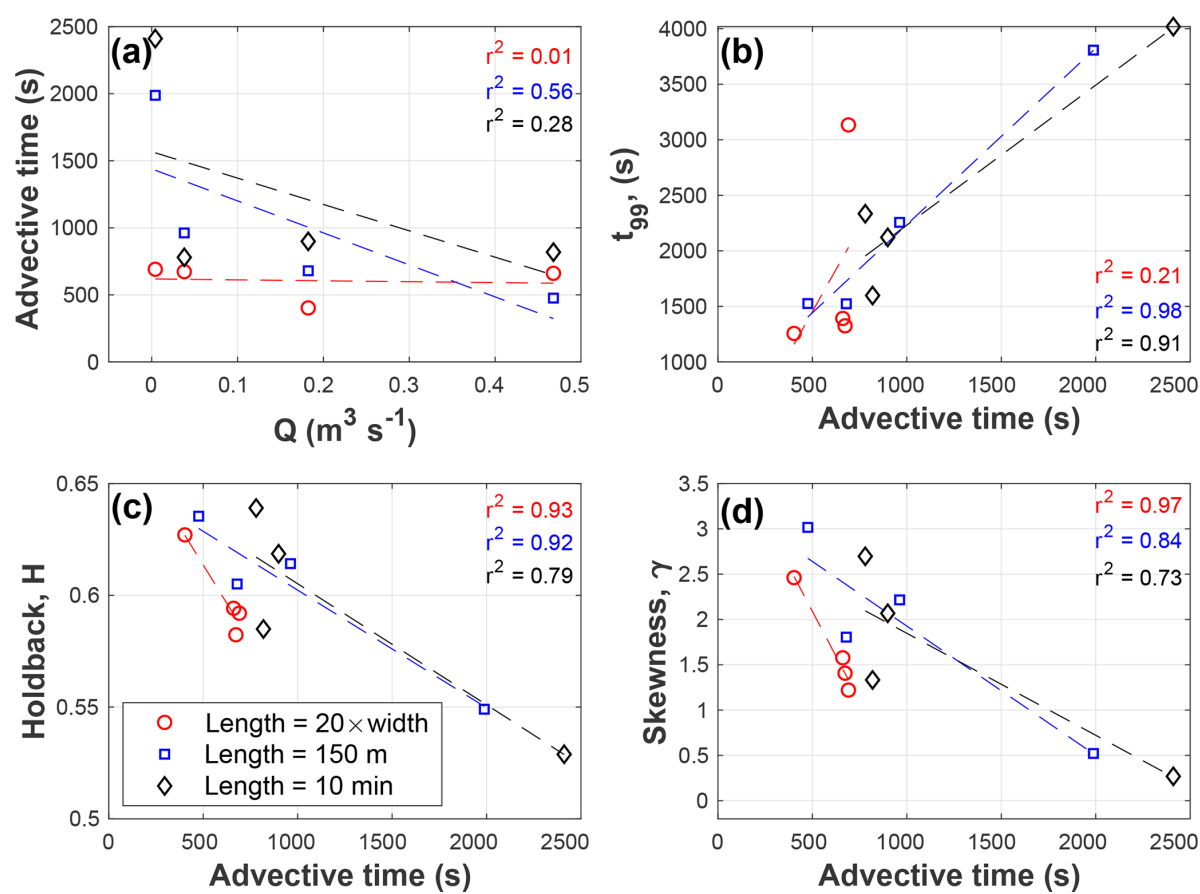

Figure 5. Comparison of fixed-reach $(150 \mathrm{~m})$, adaptive-reach length (20 wetted channel widths), and fixed-advective-time (10 min) approaches for standardization of stream solute tracer studies. (a) Control of advective time across 4 stream orders. Additional panels show the observations and a best-fit linear regression for (b) longest detection timescale, (c) holdback, and (d) skewness in relation to the advective time of the study. Best-fit linear regressions are shown as dashed lines in each panel.

and $f_{\text {QLOSS,Max }}$ generally decrease in parameter value with increase in catchment area (Fig. 6b-f). This finding is in agreement with the conceptual model of Wondzell (2011), who predicted $Q_{\mathrm{HEF}} / Q$ would decrease as drainage area increased. We did find an increasing fraction of total discharge sampled in higher-discharge locations (Fig. 4c), but the overall trend indicates that $Q_{\mathrm{HEF}}$ does not grow as rapidly as $Q$, moving downstream along the network. This is consistent with findings of decreased river corridor exchange in network locations with larger discharge (e.g., Covino et al., 2011; Ward et al., 2013c).

Two explanations have been posed relating river corridor exchange to time-variable baseflow in a given study reach, both of which result in less exchange under higher-discharge conditions. First, many conceptual models would predict that increasing baseflow is associated with increasing groundwater discharge to the stream, resulting in compression of hyporheic zones and decreased river corridor exchange (Hakenkamp et al., 1993; Hynes, 1983; Palmer, 1993; Vervier et al., 1992; White, 1993). Second, exchange may change little during storm events because, under a wide range of discharge conditions, the effect of the geomorphic features driving exchange flows may be relatively static (Ward et al., $2017 \mathrm{~b}$ ). Thus, if $Q_{\mathrm{HEF}}$ is relatively static, as $Q$ increases the relative amount of relative exchange $\left(Q_{\mathrm{HEF}} / Q\right)$ will decrease. Both explanations appear logical and suggest that river corridor exchange should change systematically with discharge. However, we did not find a consistent pattern in our synoptic field study. Rather, of the diverse array of metrics used to characterize river corridor exchange in the synoptic study, some increased and some decreased with increasing discharge. We found similarly contradictory results among our fixed-reach studies. For example, only two of 11 fixed reaches exhibited the expected negative relationship based on skewness (one indicator of $Q_{\mathrm{HEF}} / Q$ ) and discharge (Table 4).

\subsection{Heterogeneity in the river network}

The conceptual model of Wondzell (2011) followed general predictions about systematic changes in channel morphology with increasing stream size, predicting channel width, channel depth, and flow velocity will all increase with discharge, both over time at a fixed cross section or with location at a given time within a stream network. Further, bed sediment size distributions would generally decrease in a downstream direction (see, for example, Leopold and Maddock, 1953). While the physical attributes we measured at our synoptic sites did show systematic variation, the pattern in saturated hydraulic conductivity $(K)$ was contrary to expectations, as we found $K$ increased in the downstream direction (Fig. 3d). This change was so large that it overwhelmed the effect of decreasing longitudinal gradient so that the hyporheic potential actually increased in a downstream direc- 

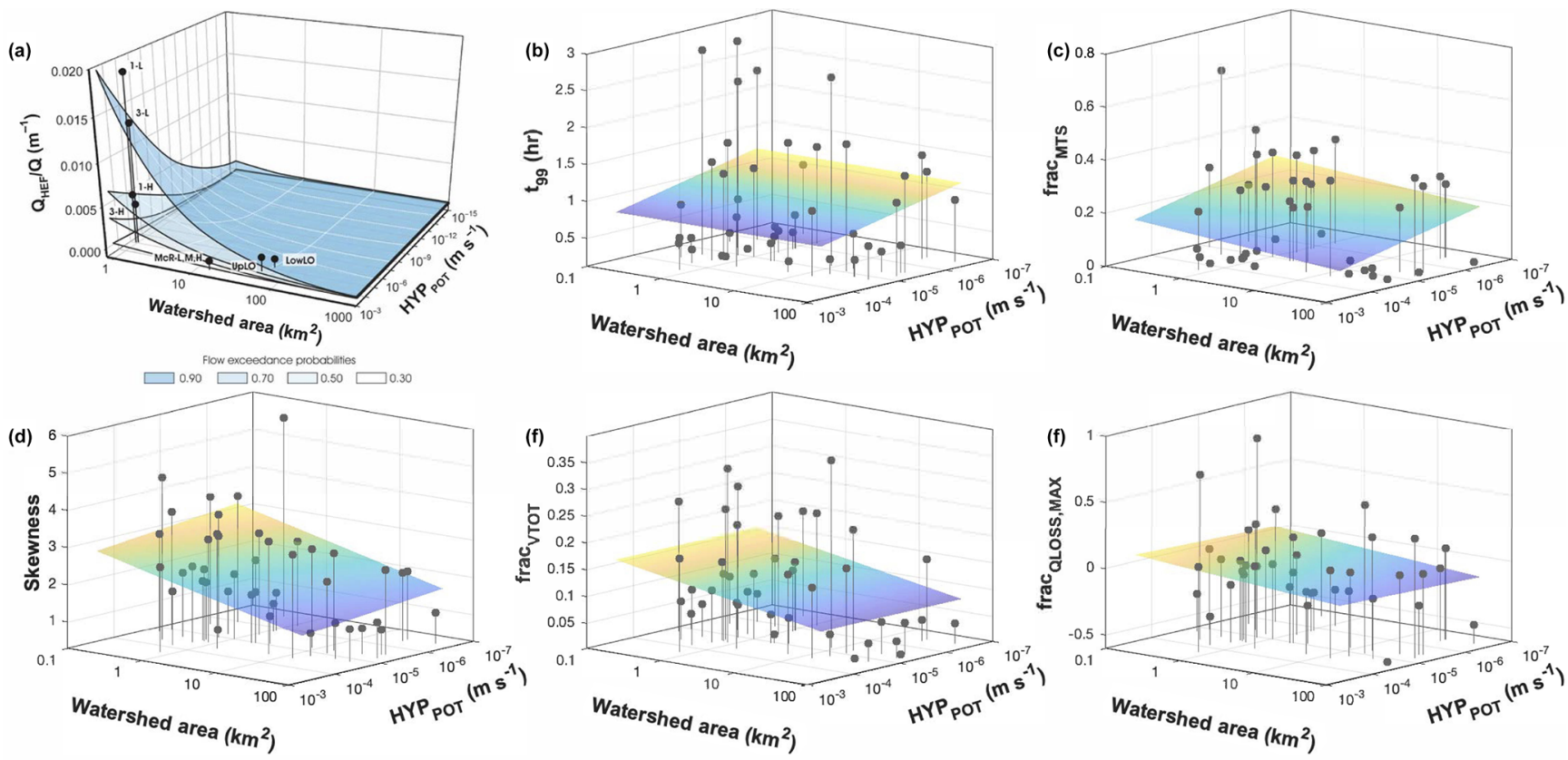

Figure 6. Comparison of (a) conceptual model of river corridor exchange (reprinted from Wondzell (2011) with permission) and findings from this study including a best-fit planar surface fit to the synoptic data for each panel (dots show the data points, and stems extend to the bottom $X-Y$ plane to aid in visualization; planar surface light-to-dark shading indicates high to low for the $z$ axis variable). Panels show trends for a subset of variables representing (b) experimental design, (c) separation of advection-dispersion from transient storage, (d) short-term storage, (e) StorAge Selection, and (f) long-term storage. Goodness of fit and slopes for each fit are summarized in Table S3.

tion. We note, however, that our studies only spanned about 4 orders of magnitude in hyporheic potential while the model of Wondzell (2011) visualizes a range that spans 14 orders of magnitude. Our study is also limited to the upper end of the range in hyporheic potential depicted by Wondzell (2011).

Our dataset also showed substantial spatial heterogeneity in all metrics along the river corridor. While the conceptual model of Wondzell (2011) does not expressly disallow such heterogeneity, the data points he used to develop the conceptual model suggest very uniform changes with watershed area and little change in hyporheic potential from 2nd- to 5th-order reaches within the same mountain stream network studied here. Our results suggest that the influence of reachscale heterogeneity among sites may be as large as, or even larger than, the expected systematic changes with watershed size. We also note that our results may differ from those of Wondzell (2011) for methodological differences. First, Wondzell (2011) based his estimates of $K$ from extensive well networks at each of his sites, using the geometric mean of all wells - including many wells on the floodplain adjacent to the stream as well as piezometers installed through the streambed. This study estimated $K$ from a single $50 \mathrm{~cm}$ deep piezometer located in the channel thalweg, and the data of Wondzell (2011) show that $K$ is higher in piezometers inserted into the shallow streambed than in floodplain sediment adjacent to the stream. Second, Wondzell (2011) used numerical simulations from groundwater flow models to cal- culate $Q_{\mathrm{HEF}}$, whereas exchange metrics in this study were derived from stream solute tracer injections. Solute injections are sensitive to both surface (in-stream) and subsurface transient storage, and metrics derived from these studies have a known bias toward the shortest transit times (Harvey et al., 1996; Wagner and Harvey, 1997; Harvey and Wagner, 2000), a bias that is clearly evident in our data. For example, the longest timescale flow path detectable, interpreted from $t_{99}$, in our study reaches ranged from about $8 \mathrm{~min}$ to $2.8 \mathrm{~h}$. In contrast, the simulations of Wondzell (2011) included flow paths with up to $10 \mathrm{~d}$ transit times. However, cell sizes in the finite-difference grids used in his models limited the shortest flow paths that could be simulated, so his estimates of $Q_{\mathrm{HEF}}$ should underrepresent the very shortest flow paths present within the reach.

Transient storage in the surface (in-stream) channel is known to influence tracer breakthrough in solute injection experiments and more specifically has been documented in our study basin (Jackson et al., 2012, 2013). Thus, our data represent a combination of surface and hyporheic transient storage, but we expect the hyporheic component will be most sensitive to hydraulic conductivity. Thus, deviation from the expected trend with hyporheic potential may simply indicate that our tracer studies were not solely representative of $Q_{\mathrm{HEF}}$ between a stream and its hyporheic zone as defined and assumed by Wondzell (2011) (Fig. 6). Our SAS analyses indicate we measured storage volumes larger than the stream 
in most reaches, but it is unclear what the mechanisms or timescales of exchange were for the storage locations measured. Overall, this unique basin-scale dataset does not appear to support the conceptual model of Wondzell (2011) with respect to hyporheic potential, but it does not disprove it either due to the limitations in methods, and clustering on only the highest end of the axis likely biased our results. Still, we suggest local-scale processes specific to individual sites may overwhelm basin-scale trends and limit the ability of continuum-based conceptual models, such as that of Wondzell (2011), to predict local-scale hyporheic and river corridor exchange dynamics.

\subsection{Can space-for-time or time-for-space relationships be used to transfer findings based on reach-scale characteristics?}

Transferability of findings in space or time relies upon two assumptions, both of which are necessary conditions for reliable prediction. First, transferability requires that the process of interest varies systematically with at least one observable variable at the study and predicted sites. In our case, this requires the relationship between discharge and river corridor exchange to be measurable and robust, commonly judged on the basis of a goodness-of-fit metric for a regression. Transferability also requires that the functional form established from the observations holds for the conditions that are being predicted. In the temporal domain this is most commonly interpolation in time to predict river corridor exchange under a discharge condition that was not actually observed (e.g., Harman et al., 2016; Ward et al., 2018a). In the spatial domain, this transferability strategy may manifest as interpolation between observed sites (e.g., Covino et al., 2011; Mallard et al., 2014) or extrapolation to sites that are morphologically similar, such as extending findings from one headwater site to make predictions in an adjacent basin or another stream reach (e.g., Jencso et al., 2011; Covino et al., 2011; Stewart et al., 2011). This approach assumes that the relationship holds because the observational and predicted sites are similar. However, we find that there is substantial variation among sites, particularly when reaches of similar size yield opposing relationships with explanatory variables (Tables 2, 3).

Overall, we conclude that discharge alone is a poor predictor of river corridor exchange in mountain stream networks due to heterogeneity in reach-scale geomorphic settings and should not be used as the sole basis for spatial or temporal extrapolation of findings. We found opposing relationships between river corridor exchange and discharge through space (synoptic approach) and time (fixed-reach approach). For all metrics considered, at least $18 \%$ (two of 11) of the intensively studied fixed reaches had trends opposite of what would be predicted from the one-time sampling of the synoptic study. Moreover, the opposing trends were always located across at least two different landform types, and there were examples of within-landform-type disagreement for ev- ery metric considered. Furthermore, the regressions we developed indicated that there was substantial inter-site heterogeneity overriding the observed network-scale trends. These findings are useful for identifying best practices to ultimately develop better scaling relationships to predict river corridor exchange as a function of hydrologic forcing and geomorphic setting from headwaters to oceans. For example, intensively studying a small number of study reaches is not indicative of the conditions occurring across an entire basin, even at the scale of our 5th-order basin. We further develop suggestions for best practices and considerations in the next section.

\subsection{Best practices to measure and interpret exchange-discharge relationships}

Stream solute tracers are perhaps the empirical method most frequently used to measure river corridor exchange. Given the relative ease and low cost of this method, it is unsurprising that many studies have used solute tracer studies under different discharge conditions to assess relationships between discharge and river corridor exchange. For example, some studies repeat solute injections in a fixed reach under a range of discharge conditions during different seasons (e.g., Zarnetske et al., 2007; Ward et al., 2018b), during baseflow recession (e.g., Payn et al., 2009; Ward et al., 2012), or during storm events (e.g., Ward et al., 2013b; Dudley-Southern and Binley, 2015). Still others use spatial replication at multiple sites within a network to construct a relationship that can be used to predict behavior for unstudied reaches during a single discharge condition (e.g., Jencso et al., 2011; Covino et al., 2011; Stewart et al., 2011). However, limitations of stream solute tracers are well documented in the literature as mentioned above (Harvey et al., 1996; Wagner and Harvey, 1997; Harvey and Wagner, 2000; Drummond et al., 2012; Kelleher et al., 2013; Ward et al., 2017a).

The ability to detect late-time tailing of the tracer (e.g., Drummond et al., 2012) and parameter dependence on advective timescales of transport (e.g., Schmadel et al., 2016a) limit the interpretability of solute tracer studies. However, armed with a seemingly straightforward tools (e.g., stream solute tracers) and the expectation to find trends with discharge, it is logical that many studies have concluded discharge (or its tightly correlated proxy of drainage area) is a meaningful predictor of river corridor exchange. However, we argue this may be a self-fulfilling prophecy as it is often unclear exactly what is being measured by the tracer observations. For fixed-reach studies repeated under different discharge conditions, the observed trends between river corridor exchange and discharge can be plausibly explained by either physical transport processes or simply limitations of the tracer method. Indeed, this unfortunate conclusion was clearly illustrated by recent studies focused on solute tracer studies across a range of discharge conditions (e.g., Wondzell, 2006; Schmadel et al., 2016a). Thus, we contend that it is unknown if reported trends in the literature reflect 
mechanistic understanding of the river corridor or suffer from confirmation bias. Therefore, we detail two best practices for conducting and interpreting stream solute tracer tests for those seeking to do as we have attempted in this study.

\subsubsection{Best practice 1: control for advective timescales instead of reach length}

The most common paradigm in stream solute tracer studies is to use a fixed-length study reach and hold length constant to compare different reaches (e.g., Payn et al., 2009; Covino et al., 2011) or to compare different discharge conditions at a single reach of fixed length (e.g., Schmadel et al., 2016a; Ward et al., 2013a). The implicit logic is that by fixing the reach length, the same morphologic features interact with the tracer and allow the researcher to measure changes in the same processes. However, this is only true in the case where the same suite of flow paths can be detected. When advective timescales decrease, the window of detection (i.e., the longest timescale flow path that can be detected) should decrease in response (e.g., Schmadel et al., 2016a). As a result, the fixed reach causes systematic bias in the tracer experiment. Higher discharges will have smaller windows of detection, biasing the results toward shorter timescale flow paths compared to low-discharge injections.

Based on our findings (Fig. 5), plus the well-documented interaction of advective timescale with river corridor exchange measured with solute tracers, we strongly recommend experimental designs that control for advective timescale. We suggest that an upstream location be established and fixed in space. Then the length of the study reach should be determined, either by scaling by channel width (e.g., 20 times the wetted channel width) or by using a dye tracer to measure advective velocity over a length equal to perhaps 10 wetted channel widths, and then using advective velocity to calculate a study reach length that provides uniform advective travel times in all reaches studied.

When tracer injections are designed to provide uniform advective travel times, the resulting study reach lengths will be longest in the largest streams and/or at times of high discharge; reaches will be shortest under low-discharge conditions. It is critical that the shortest reach length still encompasses a length of stream that is sufficient to integrate representative variation in morphology of the study system. If reaches are too short, high reach-to-reach variability will be generated by one or a few morphologic features and these local conditions are likely to dominate comparisons among reaches and make it difficult to discern the influence of changing hydrologic conditions. It will be difficult to determine a length-scale long enough to integrate the full range of morphologic features present in any given stream. Schmadel et al. (2014) suggested that a morphologically representative reach could be determined by knowing the length of spatial autocorrelation of morphologic features, but this requires substantial effort to survey or map the study reach prior to conducting a tracer test. A less effort-intensive but more equipment-intensive approach would be to place multiple sensors in the study reach (perhaps 10, 20, 35, 50, 75, and 100 wetted channel widths) and select most appropriate downstream breakthrough curves to compare based on similarity of advective timescales after conducting the tracer test.

It is also essential that measures of the advective timescale and window of detection be reported for each tracer test. For slug injections these would include $t_{\text {peak }}$ and $t_{99}$. For constant rate injections these would be time to the steepest point on the rising limb, time to median arrival $\left(M_{1}\right)$, and time to achieve plateau. The $L_{\text {detect }}$ estimates should also be reported and these should be based on time to achieve plateau as that indicates when the tracer has traveled the full length of all measurable flow paths and only tracer-labeled water is being returned to the stream. These metrics describing the advective timescale are necessary both to confirm that comparisons among reaches in any given study are valid and to facilitate comparisons of results among published studies.

We acknowledge here that the steps we have recommended above will require substantial time and analysis to design a stream tracer experiment. However, we contend this additional work is necessary to maximize the interpretability of the data and enable meaningful comparison across space and time.

\subsubsection{Best practice 2: critical evaluation of which flow paths may have been measured by the experiment}

One persistent limitation of interpreting stream solute tracers is the inability to know which flow paths and features were actually measured in the study reach. While additional observations in storage zones have been attempted via monitoring wells or geophysical imaging, multiple studies show that solute observed in the storage zone itself is not necessarily meaningful, as the stream breakthrough curve integrates only a subset of flow paths (Ward et al., 2010a, 2017b, Toran et al., 2012, 2013). Briggs et al. (2009) suggest additional measurements in the surface storage domain may allow for parsing surface from subsurface transient storage. However, this approach relies upon measurement of a representative instream storage zone and interpretation via the transient storage model, which is known to be limited in identifiability of parameters and transferability to other sites (e.g., Kelleher et al., 2013; Ward et al., 2017a).

One simple approach to estimate the spatial and temporal scales of the measured flow paths is to consider the truncation of the breakthrough curve itself. The window of detection describes the longest flow path timescale that may have been measured. Several studies have converted this timescale to a length scale using Darcy's law and parameterized it with representative values for hydraulic conductivity, porosity, and valley slope as a proxy for hydraulic gradient (after Ward et al., 2017b, 2018a). While imperfect, this interpretation at least indicates a spatial scale of flow paths that may have 
been observed. For example, in previous studies of a small stream in the HJA basin (WS01, Fig. 1), where extensive penetration of the tracer into the subsurface was documented across a $10+m$ wide valley bottom (Voltz et al., 2013; Ward et al., 2017b), the longest flow paths detected by a tracer returning to the stream still only averaged $0.21 \mathrm{~m}$ (range 0.004 to $1.2 \mathrm{~m}$ ) compared to overall reach lengths of tens of meters. This means that these studies were measuring in-stream storage and only the shortest and fastest subsurface flow paths not integrating all the exchange in the valley bottom.

The SAS approach implemented in this study provides some valuable additional contextual information about the storage volume and discharge that informs interpretation of findings. For example, our synoptic study labeled an average of $86 \%$ of the outflowing discharge in the surface channel (range $57 \%$ to $95 \%$ ). Still, this equated to having only sampled an average of $12 \%$ of the total storage volume in the reach (range $0.3 \%$ to $35 \%$ ), suggesting a bias toward in-stream storage. This bias is confirmed by the realization that, on average, only $18 \%$ of tracer mass was involved in transient storage (range $0 \%$ to $69 \%$ ). Hence, the SAS approach gives us additional insights and reveals biases in the tracer methods. Altogether, this study clearly indicates that multiple data collection, analysis, and modeling techniques are needed to develop scaling relationships representative of river corridor exchange across varying hydrologic forcing and geomorphic settings.

\section{Conclusions}

We set out to leverage novel datasets collected across a 5thorder basin to test the existence of systematic relationships linking river corridor exchange with temporal variation in discharge, spatial patterns in discharge, and local geomorphic setting. We specifically intended to use these data to critically test the conceptual model of Wondzell (2011) (Fig. 6a). We found systematic patterns, namely decreases in several indicators of river corridor exchange with increasing discharge in space (i.e., moving downstream in the network), confirming this part of the Wondzell (2011) conceptual model. The model of Wondzell (2011) predicts the same trend for increasing baseflow discharge in time, but we found both direct and inverse relationships between river corridor exchange and discharge at fixed reaches under varied baseflow conditions. These findings reflect a high degree of heterogeneity on a reach-to-reach basis in space, likely overwhelming or obscuring river corridor exchange patterns that might emerge in more spatially continuous and larger-scale assessments, which would be a better test of the Wondzell (2011) model. Importantly, we document consistent trends with discharge that have low explanatory power (low $r^{2}$ ) despite being statistically significant in their direction, indicating that we have little predictive power. Moreover, our findings reveal the challenges that must be addressed to design and interpret stream solute data among sites or discharge conditions. Finally, we did not confirm the predicted pattern of Wondzell (2011) with respect to local hyporheic potential at a site, which may have been confounded by integration of both surface and hyporheic storage by the stream solute tracers or by local-scale heterogeneity not captured in our reach-scale site characterization. Collectively, the larger Sen's slopes for the fixed reaches, when compared across variable hydrologic conditions, may indicate more temporal variation at a site through the season than there is through the network under the single baseflow condition. This means that caution is needed in applying synoptic sampling approaches across time when studying river corridor exchange conditions in a river network.

This study documented the interaction between advective travel times and measurement of river corridor exchange with solute tracers. Our synoptic study design controlled for this complication by scaling study reach lengths based on wetted channel width. For future studies focused on exchangedischarge relationships, we suggest two best practices. First, we suggest controlling for advective time to measure consistent timescales of storage processes and limit artifacts that are due to limitations of solute tracer studies. Second, we suggest analyses that focus on the fractions of storage volume and outflow that were labeled with tracer to provide context for interpreting recovered time series. We also note that many previous studies have relied upon small sample sizes and focused on singular explanatory variables of interest considered in isolation. We suggest this is primarily descriptive, and we conclude that consideration of multiple interacting controls will be necessary to achieve predictive understanding of river corridor exchange across varying hydrologic forcing and geomorphic setting from headwaters to large river networks.

Finally, we underscore that a one-time synoptic sampling campaign does not address local-scale variability that is created by variable discharge conditions, nor does extensive study of a single reach provide data that are reflective of variation in space in the river network. In short, space-for-time and time-for-space substitutions based on the methods used in our study are not a reliable basis for transferability or prediction.

Data availability. All data used in this study are archived in the Consortium of Universities for the Advancement of Hydrologic Science, Inc. (CUAHSI) HydroShare data repository, publicly accessible at https://doi.org/10.4211/hs.f4484e0703f743c696c2e1f209abb842 (Ward et al., 2019). 


\section{Appendix A: Summary of symbols used in this paper}

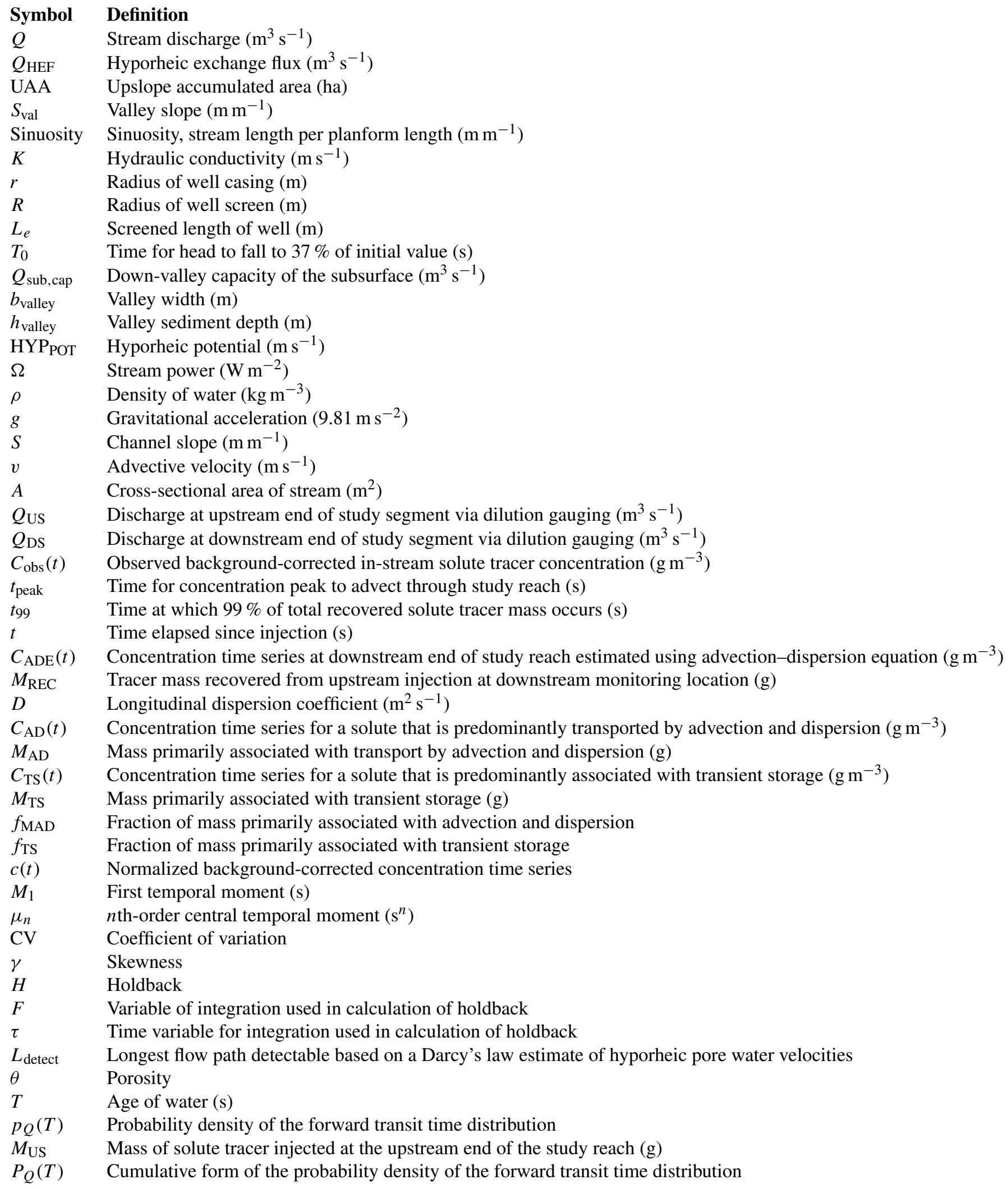




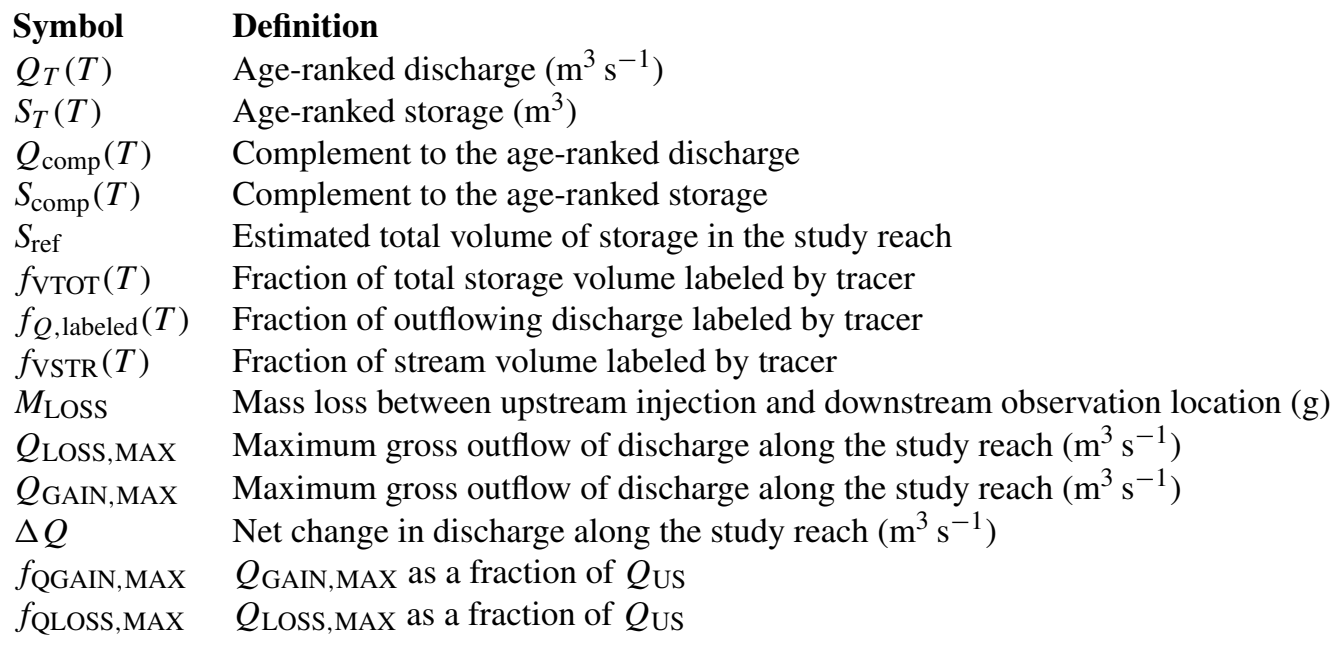


Supplement. The supplement related to this article is available online at: https://doi.org/10.5194/hess-23-5199-2019-supplement.

Author contributions. ASW, SMW, JPZ, and NMS conceptualized the work. All co-authors contributed to methodology, review, and editing of the paper. ASW completed formal analysis, visualization, project administration, and data curation. Original draft preparation was completed by ASW, SMW, NMS, and SPH. Data collection was completed by ASW, NMS, JPZ, VB, PJB, NB, RC, RD, JD, VGC, EG, DH, CH, JH, JLAK, SK, MJK, AL, EM, MM, AMM, KN, LO, SP, LR, KR, TR, CS, JS, ST, JW, and NIW. Project resources were provided by ASW, JPZ, VB, RC, JF, EG, DH, CJH, SK, JL, EM, AMM, LO, AIP, LR, TR, CS, JS, JT, and JW with funding acquisition by ASW, JPZ, RC, JF, EH, SK, JL, EM, and AMM.

Competing interests. The authors declare that they have no conflict of interest.

Special issue statement. This article is part of the special issue "Linking landscape organisation and hydrological functioning: from hypotheses and observations to concepts, models and understanding (HESS/ESSD inter-journal SI)". It is not associated with a conference.

Acknowledgements. Data and facilities were provided by the H. J. Andrews Experimental Forest and Long Term Ecological Research program, administered cooperatively by the USDA Forest Service Pacific Northwest Research Station, Oregon State University, and the Willamette National Forest. Any use of trade, firm, or product names is for descriptive purposes only and does not imply endorsement by the US government. Any opinions, findings, and conclusions or recommendations expressed in this material are those of the authors. Finally, the authors acknowledge this would not have been possible without support from their home institutions.

Financial support. This research has been supported by the Leverhulme Trust (Where rivers, groundwater and disciplines meet: a hyporheic research network), the UK Natural Environment Research Council (grant no. NE/L003872/1), the European Commission, H2020 Marie Skłodowska-Curie Actions (HiFreq (grant no. 734317)), the U.S. Department of Energy (Pacific Northwest National Lab and DE-SC0019377), the National Science Foundation (grant nos. DEB-1440409, EAR-1652293, EAR-1417603, and EAR-1446328), and the University of Birmingham (Institute of Advanced Studies).

Review statement. This paper was edited by Loes van Schaik and reviewed by Matt Cohen and one anonymous referee.

\section{References}

Anderson, J. K., Wondzell, S. M., Gooseff, M. N., and Haggerty, R.: Patterns in stream longitudinal profiles and implications for hyporheic exchange flow at the H. J. Andrews Experimental Forest, Oregon, USA, Hydrol. Process., 19, 2931-2949, 2005.

Bencala, K. E. and Walters, R. A.: Simulation of solute transport in a mountain pool-and-riffle stream: a transient storage model, Water Resour. Res., 19, 718-724, https://doi.org/10.1029/WR019i003p00718, 1983.

Bertuzzo, E., Helton, A. M., Hall Jr., and R. O., Battin, T. J.: Scaling of dissolved organic carbon removal in river networks, Adv. Water Res., 110, 136-146, 2017.

Brardinoni, F. and Hassan, M. A.: Glacially induced organization of channel-reach morphology in mountain streams, J. Geophys. Res.-Earth, 112, 1-18, https://doi.org/10.1029/2006JF000741, 2007.

Briggs, M. A., Gooseff, M. N., Arp, C. D., and Baker, M. A.: A method for estimating surface transient storage parameters for streams with concurrent hyporheic storage, Water Resour. Res., 45, W00D27, https://doi.org/10.1029/2008WR006959, 2009.

Brummer, C. J. and Montgomery, D. R.: Downstream coarsening in headwater channels, Water Resour. Res., 39, 1294, https://doi.org/10.1029/2003WR001981, 2003.

Brunke, M. and Gonser, T.: The ecological significance of exchange processes between rivers and groundwater, Freshwater Biol., 37, 1-33, 1997.

Butturini, A. and Sabater, F.: Importance of transient storage zones for ammonium and phosphate retention in a sandy-bottom Mediterranean stream, Freshwater Biol., 41, 593-603, 1999.

Cashman, K. V., Deligne, N. I., Gannett, M. W., Grant, G. E., and Jefferson, A.: Fire and water: Volcanology, geomorphology, and hydrogeology of the Cascade Range, central Oregon, F. Guid., 15, 539-582, 2009.

Church, M. and Zimmermann, A.: Form and stability of steppool channels: Research progress, Water Resour. Res., 43, 1-21, https://doi.org/10.1029/2006WR005037, 2007.

Corson-Rikert, H. A., Wondzell, S. M., Haggerty, R., and Santelmann, M. V: Carbon dynamics in the hyporheic zone of a headwater mountain streamin the Cascade Mountains, Oregon, Water Resour. Res., 52, 7556-7576, 2016.

Covino, T., McGlynn, B., and Baker, M., Separating physical and biological nutrient retention and quantifying uptake kinetics from ambient to saturation in successive mountain stream reaches, J. Geophys. Res., 115, G04010, https://doi.org/10.1029/2009JG001263, 2010.

Covino, T. P., McGlynn, B. L., and Mallard, J.: Stream-groundwater exchange and hydrologic turnover at the network scale, Water Resour. Res., 47, W12521, 2011.

Crook, N., Binley, A., Knight, R., Robinson, D. A., Zarnetske, J., and Haggerty, R.: Electrical resistivity imaging of the architecture of substream sediments, Water Resour. Res., 44, W00D13, https://doi.org/10.1029/2008WR006968, 2008.

Day, T. J.: Field procedures and evaluation of a slug dilution gauging method in mountain streams, J. Hydrol. N. Z., 16, 113-133, 1977.

Danckwerts, P.: Continuous flow systems. Distribution of residence times, Chem. Eng. Sci., 2, 1-13, 1953.

Deligne, N. I., Mckay, D., Conrey, R. M., Grant, G. E., Johnson, E. R., O'Connor, J., and Sweeney, K.: Field-trip guide to mafic 
volcanism of the Cascade Range in central Oregon - A volcanic, tectonic, hydrologic, and geomorphic journey: U.S. Geological Survey Scientific Investigations Report 2017-5022-H, 94 pp., https://doi.org/10.3133/sir20175022H, 2017.

Domenico, P. A. and Schwartz, F. W.: Physical and Chemical Hydrogeology, John Wiley and Sons, NY, p. 824, 1990.

Drummond, J. D., Covino, T. P., Aubeneau, A. F., Leong, D., Patil, S., Schumer, R., and Packman, A. I.: Effects of solute breakthrough curve tail truncation on residence time estimates: A synthesis of solute tracer injection studies, J. Geophys. Res.-Biogeo., 117, 1-11, https://doi.org/10.1029/2012JG002019, 2012.

Dudley-Southern, M. and Binley, A.: Temporal responses of groundwater-surface water exchange to successive storm events, Water Resour. Res., 51, 1112-1126, https://doi.org/10.1002/2014WR016623, 2015.

Dyrness, C. T.: Hydrologic properties of soils on three small watersheds in the western Cascades of Oregon, USDA For. SERV RES NOTE PNW-111, SEP 1969, 17 pp., 1969.

Fabian, M. W., Endreny, T. A., Bottacin-Busolin, A., and Lautz, L. K.: Seasonal variation in cascade-driven hyporheic exchange, northern Honduras, Hydrol. Process., 25, 1630-1646, https://doi.org/10.1002/hyp.7924, 2011.

Gerecht, K. E., Cardenas, M. B., Guswa, A. J., Sawyer, A. H., Nowinski, J. D., and Swanson, T. E.: Dynamics of hyporheic flow and heat transport across a bed-to-bank continuum in a large regulated river, Water Resour. Res., 47, W03524, https://doi.org/10.1029/2010wr009794, 2011.

Gomez-Velez, J. D. and Harvey, J. W.: A hydrogeomorphic river network model predicts where and why hyporheic exchange is important in large basins, Geophys. Res. Lett., 41, 6403-6412, https://doi.org/10.1002/2014GL061099, 2014.

Gomez-Velez, J. D., Harvey, J. W., Cardenas, M. B., and Kiel, B.: Denitrification in the Mississippi River network controlled by flow through river bedforms, Nat. Geosci., 8, 1-8, https://doi.org/10.1038/ngeo2567, 2015.

Gooseff, M. N., Anderson, J. K., Wondzell, S. M., LaNier, J., and Haggerty, R.: A modelling study of hyporheic exchange pattern and the sequence, size, and spacing of stream bedforms in mountain stream networks, Oregon, USA, Hydrol. Process., 20, 24432457, 2006.

Gooseff, M. N., Hall, R. O., and Tank, J. L.: Relating transient storage to channel complexity in streams of varying land use in Jackson Hole, Wyoming, Water Resour. Res., 43, 1-10, https://doi.org/10.1029/2005WR004626, 2007.

Gupta, A. and Cvetkovic, V.: Temporal moment analysis of tracer discharge in streams: combined effect of physicochemical mass transfer and morphology, Water Resour. Res., 36, 2985-2997, 2000.

Haggerty, R. and Reeves, P.: STAMMT-L Version 1.0 User's Manual, Sandia Natl. Lab. [ERMS\# 520308], 1-76, 2002.

Hakenkamp, C. C., Valett, H. M., and Boulton, A. J.: Perspectives on the Hyporheic Zone: Integrating Hydrology and Biology. Concluding remarks, J. North Am. Benthol. Soc., 12, 94-99, https://doi.org/10.2307/1467683, 1993.

Harman, C. J.: Time-variable transit time distributions and transport: Theory and application to storage-dependent transport of chloride in a watershed, Water Resour. Res., 51, 1-30, https://doi.org/10.1002/2014WR015707, 2015.
Harman, C. J., Ward, A. S., and Ball, A.: How does reachscale stream-hyporheic transport vary with discharge? Insights from rSAS analysis of sequential tracer injections in a headwater mountain stream, Water Resour. Res., 52, 7130-7150, https://doi.org/10.1002/2016WR018832, 2016.

Harms, T. K., Cook, C. L., Wlostowski, A. N., Gooseff, M. N., and Godsey, S. E.: Ecosystems. Spiraling Down Hillslopes: Nutrient Uptake from Water Tracks in a Warming Arctic, Ecosystems, 15 pp., https://doi.org/10.1007/s10021-019-00355-z, 2019.

Hart, D. R., Mulholland, P. J., Marzolf, E. R., DeAngelis, D. L., and Hendricks, S. P.: Relationships between hydraulic parameters in a small stream under varying flow and seasonal conditions, Hydrol. Process., 13, 1497-1510, 1999.

Harvey, J. W. and Gooseff, M. N.: River corridor science: Hydrologic exchange and ecological consequences from bedforms to basins, Water Resour. Res., 51, 6893-6922, https://doi.org/10.1002/2015WR017617, 2015.

Harvey, J. W. and Wagner, B. J.: Quantifying hydrologic interactions between streams and their subsurface hyporheic zones, in: Streams and Ground Waters, edited by: Jones, J. B. and Mulholland, P. J., 3-44, 2000.

Harvey, J. W., Wagner, B. J., and Bencala, K. E.: Evaluating the reliability of the stream tracer approach to characterize streamsubsurface water exchange, Water Resour. Res., 32, 2441-2451, 1996.

Harvey, J. W., Gomez-Velez, J. D., Alexander, R. B., Eng, K., Moore, R., Pizzuto, J., Schmadel, N., Scott, D., Golden, H., Kettner, A., Schwarz, G., Soulsby, C., Boyer, E., Konrad, C., and Choi, J.: How Hydrologic Connectivity Regulates Water Quality in River Corridors, J. Am. Water Resour. As., 55, 369-381, https://doi.org/10.1111/1752-1688.12691, 2018.

Helton, A. M., Hall, Jr., R. O., and Bertuzzo, E.: How network structure can affect nitrogen removal by streams, Freshwater Biol., 63, 128-140, 2018.

Hvorslev, M. J.: Time lag and soil permeability in ground-water observations, Bull No. 36, 50 pp., U.S. Army Waterways Experiment Station, Vicksburg, MS, 1951.

Hynes, H. B. N.: Groundwater and stream ecology, Hydrobiologia, 100, 93-99, 1983.

Jackson, T. R., Haggerty, R., Apte, S. V., Coleman, A., and Drost, K. J.: Defining and measuring the mean residence time of lateral surface transient storage zones in small streams, Water Resour. Res., 48, 1-20, https://doi.org/10.1029/2012WR012096, 2012.

Jackson, T. R., Haggerty, R., Apte, S. V., and O'Connor, B. L.: A mean residence time relationship for lateral cavities in gravel-bed rivers and streams: Incorporating streambed roughness and cavity shape, Water Resour. Res., 49, 3642-3650, https://doi.org/10.1002/wrcr.20272, 2013.

Jefferson, A., Grant, G. E., and Lewis, S. L.: A River Runs Underneath It: Geological Control of Spring and Channel Systems and Management Implications, Cascade Range, Oregon, in: Advancing the Fundamental Sciences Proceedings of the Forest Service: Proceedings of the Forest Service National Earth Sciences Conference, vol. 1, 18-22, 2004.

Jencso, K. G. and McGlynn, B. L.: Hierarchical controls on runoff generation: Topographically driven hydrologic connectivity, geology, and vegetation, Water Resour. Res., 47, W11527, https://doi.org/10.1029/2011wr010666, 2011. 
Jin, H. S. and Ward, G. M.: Hydraulic characteristics of a small Coastal Plain stream of the southeastern United States: Effects of hydrology and season, Hydrol. Process., 19, 4147-4160, https://doi.org/10.1002/hyp.5878, 2005.

Johnson, S. L.: Factors influencing stream temperatures in small streams: substrate effects and a shading experiment, Can. J. Fish. Aquat. Sci., 61, 913-923, 2004.

Karwan, D. L. and Saiers, J. E.: Influences of seasonal flow regime on the fate and transport of fine particles and a dissolved solute in a New England stream, Water Resour. Res., 45, W11423, 2009.

Kasahara, T. and Wondzell, S. M.: Geomorphic controls on hyporheic exchange flow in mountain streams, Water Resour. Res., 39, 1005, https://doi.org/10.1029/2002WR001386, 2003.

Kelleher, C. A., Wagener, T., McGlynn, B. L., Ward, A. S., Gooseff, M. N., and Payn, R. A.: Identifiability of transient storage model parameters along a mountain stream, Water Resour. Res., 49, 5290-5306, https://doi.org/10.1002/wrcr.20413, 2013.

Kiel, B. and Cardenas, M.: Lateral hyporheic exchange throughout the Mississippi River network, Nat. Geosci., 7, 413-417, https://doi.org/10.1038/ngeo2157, 2014.

Kilpatrick, F. A. and Cobb, E. D.: Measurement of discharge using tracers, U.S. Geol. Surv., Techniques of Water-Resources Investigations, Book 3, chap. A-16, 1985.

Krause, S., Hannah, D. M., Fleckenstein, J. H., Heppell, C. M., Kaeser, D. H., Pickup, R., Pinay, G., Robertson, A. L., and Wood, P. J.: Inter-disciplinary perspectives on processes in the hyporheic zone, Ecohydrology, 4, 481-499, 2011.

Lee-Cullin, J. A., Zarnetske, J. P., Ruhala, S. S., and Plont, S.: Toward measuring biogeochemistry within the stream-groundwater interface at the network scale: an initial assessment of two spatial sampling strategies, Limnol. Oceanogr.-Meth., 16, 722-733, 2018.

Leopold, L. B. and Maddock, T.: The hydraulic geometry of stream channels and some physiographic implications, vol. 252, US Government Printing Office, 1953.

MacDonald, L. H., Smart, A. W., and Wissmar, R. C.. Monitoring guidelines to evaluate effects of forestry activities on streams in the Pacific Northwest and Alaska, 177, 1991.

Mallard, J., McGlynn, B. L., and Covino, T. P.: Lateral inflows, stream-groundwater exchange, and network geometry influence streamwater composition, Water Resour. Res., 50, 4603-4623, https://doi.org/10.1002/2013WR014222, 2014.

Malzone, J. M., Lowry, C. S., and Ward, A. S.: Response of the hyporheic zone to transient groundwater fluctuations on the annual and storm event time scales, Water Resour. Res., 52, 1-20, https://doi.org/10.1002/2014WR015716, 2016.

Martin, D. J.: The influence of geomorphic factors and geographic region on large woody debris loading and fish habitat in Alaska coastal streams, North Am. J. Fish. Manag., 21, 429-440, https://doi.org/10.1577/15488675(2001)021<0429:TIOGFA>2.0.CO;2, 2001.

Mason, S. J. K., McGlynn, B. L., and Poole, G. C.: Hydrologic response to channel reconfiguration on Silver Bow Creek, Montana, J. Hydrol., 438-439, 125-136, 2012.

Montgomery, D. R. and Buffington, J. M.: Channel-Reach Morphology in Mountain Basins, GSA Bull., 109, 596-611, 1997.

Montgomery, D. R. and Buffington, J. M.: Chapter 2: Channel processes, classification, and response, in: River Ecology and Management - Lessons from the Pacific Coastal Ecoregion, edited by: Naiman, R. and Bilby, R., Springer Verlag, New York, NY, 13-42, 1998.

Morrice, J. A., Valett, H. M., Dahm, C. N., and Campana, M. E.: Alluvial characteristics, groundwater-surface water exchange and hydrological retention in headwater streams, Hydrol. Process., 11, 253-267, 1997.

Musial, C., Sawyer, A. H., Barnes, R., Bray, S., and Knights, D.: Surface water-groundwater exchange dynamics in a tidal freshwater zone, Hydrol. Process., 30, 739-750, https://doi.org/10.1002/hyp.10623, 2016.

Palmer, M. A.: Experimentation in the Hyporheic Zone: Challenges and Prospectus, J. North Am. Benthol. Soc., 12, 84-93, 1993.

Patil, S., Covino, T. P., Packman, A. I., McGlynn, B. L., Drummond, J. D., Payn, R. A., and Schumer, R.: Intrastream variability in solute transport: Hydrologic and geomorphic controls on solute retention, J. Geophys. Res.-Earth Surf., 118, 413-422, https://doi.org/10.1029/2012JF002455, 2013.

Payn, R. A., Gooseff, M. N., McGlynn, B. L., Bencala, K. E., and Wondzell, S. M.: Channel water balance and exchange with subsurface flow along a mountain headwater stream in Montana, United States, Water Resour. Res., 45, W11427, https://doi.org/10.1029/2008WR007644, 2009.

Payn, R. A., Gooseff, M. N., McGlynn, B. L., Bencala, K. E., and Wondzell, S. M.: Exploring changes in the spatial distribution of stream baseflow generation during a seasonal recession, Water Resour. Res., 48, W04519, https://doi.org/10.1029/2011WR011552, 2012.

Rana, S. M., Scott, D. T., and Hester, E. T.: Effects of in-stream structures and channel flow rate variation on transient storage, J. Hydrol., 548, 157-169, https://doi.org/10.1016/j.jhydrol.2017.02.049, 2017.

Rana, S. M. M., Boccelli, D. L., Scott, D. T., and Hester, E. T.: Parameter uncertainty with flow variation of the onedimensional solute transport model for small streams using Markov chain Monte Carlo, J. Hydrol., 575, 1145-1154, https://doi.org/10.1016/j.jhydrol.2019.06.003, 2019.

Rot, B. W., Naiman, R. J., and Bilby, R. E.: Stream channel configuration, landform, and riparian forest structure in the Cascade Mountains, Washington, Can. J. Fish. Aquat. Sci., 57, 699-707, https://doi.org/10.1139/f00-002, 2000.

Ruhala S. S., Zarnetske, J. P., Long, D. T., Lee-Cullin, J. A., Plont, S., and Wiewiora, E. R.: Exploring dissolved organic carbon cycling at the stream-groundwater interface across a third-order, lowland stream network, Biogeochemistry, 137, 105-126, 2017.

Sawyer, A. H., Cardenas, M. B., Bomar, A., and Mackey, M.: Impact of dam operations on hyporheic exchange in the riparian zone of a regulated river, Hydrol. Process., 23, 2129-2137, 2009.

Schmadel, N. M., Neilson, B. T., and Stevens, D. K.: Approaches to estimate uncertainty in longitudinal channel water balances, J. Hydrol., 394, 357-369, 2010.

Schmadel, N. M., Neilson, B. T., Heavilin, J., Stevens, D. K., and Worman, A.: The influence of spatially variable streamhydraulics on reach scale transient storage modeling, Water Resour. Res., 50, 9287-9299, https://doi.org/10.1002/2015WR017273, 2014.

Schmadel, N. M., Ward, A. S., Kurz, M. J., Fleckenstein, J. H., Zarnetske, J. P., Knapp, J. L. A., Klaar, M. J., Romeijn, P., Datry, T., Keller, T., and Folegot, S.: Stream solute tracer timescales changing with discharge and reach length confound 
process interpretation, Water Resour. Res., 52, 3227-3245, https://doi.org/10.1002/2015WR018062, 2016a.

Schmadel, N. M., Ward, A. S., Lowry, C. S., and Malzone, J. M.: Hyporheic exchange controlled by dynamic hydrologic boundary conditions, Geophys. Res. Lett., 43, 4408-4417, https://doi.org/10.1002/2016GL068286, 2016b.

Schmadel, N. M., Ward, A. S., and Wondzell, S. M.: Hydrologic controls on hyporheic exchange in a headwater mountain stream, Water Resour. Res., 53, 6260-6278, https://doi.org/10.1002/2017WR020576, 2017.

Schmid, B. H.: Can Longitudinal Solute Transport Parameters Be Transferred to Different Flow Rates?, J. Hydrol. Eng., 13, 505509, 2008.

Schmid, B. H., Innocenti, I., San, U., and Sanfilippo, U.: Characterizing solute transport with transient storage across a range of flow rates: The evidence of repeated tracer experiments in Austrian and Italian streams, Adv. Water Resour., 33, 1340-1346, https://doi.org/10.1016/j.advwatres.2010.06.001, 2010.

Schwanghart, W. and Kuhn, N. J.: TopoToolbox: A set of Matlab functions for topographic analysis, Environ. Modell. Softw., 25, 770-781, https://doi.org/10.1016/j.envsoft.2009.12.002, 2010.

Schwanghart, W. and Scherler, D.: Short Communication: TopoToolbox 2 - MATLAB-based software for topographic analysis and modeling in Earth surface sciences, Earth Surf. Dynam., 2, 1-7, https://doi.org/10.5194/esurf-2-1-2014, 2014.

Stewart, R. J., Wollheim, W. M., Gooseff, M. N., Briggs, M. A., Jacobs, J. M., Peterson, B. J., and Hopkinson, C. S.: Separation of river network-scale nitrogen removal among the main channel and two transient storage compartments, Water Resour. Res., 47, W00J10, 2011.

Storey, R. G., Howard, K. W. F., and Williams, D. D.: Factors controlling riffle-scale hyporheic exchange flows and their seasonal changes in a gaining stream: A three-dimensional groundwater flow model, Water Resour. Res., 39, 1034, https://doi.org/10.1029/2002WR001367, 2003.

Swanson, F. J. and James, M. E.: Geology and geomorphology of the H.J. Andrews Experimental Forest, western Cascades, Oregon, Portland, OR, 1975.

Swanson, F. J. and Jones, J. A.: Geomorphology and hydrology of the HJ Andrews experimental forest, Blue River, Oregon, F. Guid. to Geol. Process. Cascadia, 36, 289-314, 2002.

Toran, L., Hughes, B., Nyquist, J. E., and Ryan, R. J.: Freeze Core Sampling to Validate Time-Lapse Resistivity Monitoring of the Hyporheic Zone, Ground Water, 51, 635-640, https://doi.org/10.1111/j.1745-6584.2012.01002.x, 2012.

Toran, L., Nyquist, J. E., Fang, A. C., Ryan, R. J., and Rosenberry, D. O.: Observing lingering hyporheic storage using electrical resistivity: Variations around stream restoration structures, Crabby Creek, PA, 2013.

Valett, H. M., Morrice, J. A., Dahm, C. N., and Campana, M. E.: Parent lithology, surface-groundwater exchange, and nitrate retention in headwater streams, Limnol. Oceanogr., 41, 333-345, https://doi.org/10.4319/lo.1996.41.2.0333, 1996.

Vervier, P., Gibert, J., Marmonier, P., Journal, S., American, N., Society, B., Mar, N., and Dole-Olivier, M. J.: A perspective on the permeability of the surface freshwater-groundwater ecotone, J. North Am. Benthol. Soc., 11, 93-102, 1992.

Voltz, T. J., Gooseff, M. N., Ward, A. S., Singha, K., Fitzgerald, M., and Wagener, T.: Riparian hydraulic gra- dient and stream-groundwater exchange dynamics in steep headwater valleys, J. Geophys. Res.-Earth, 118, 953-969, https://doi.org/10.1002/jgrf.20074, 2013.

Wagner, B. J. and Harvey, J. W.: Experimental design for estimating parameters of rate-limited mass transfer: Analysis of stream tracer studies, Water Resour. Res., 33, 1731-1741, 1997.

Ward, A. S.: The evolution and state of interdisciplinary hyporheic research, Wiley Interdiscip. Rev. Water, 3, 83-103, https://doi.org/10.1002/wat2.1120, 2015.

Ward, A. S. and Packman, A. I.: Advancing our predictive understanding of river corridor exchange, WIREs-Water, 6, e1327, https://doi.org/10.1002/wat2.1327, 2019.

Ward, A. S., Zarnetske, J. P., Baranov, V., Blaen, P. J., Brekenfeld, N., Chu, R., Derelle, R., Drummond, J., Fleckenstein, J., Garayburu-Caruso, V., Graham, E., Hannah, D., Harman, C., Hixson, J., Knapp, J. L. A., Krause, S., Kurz, M. J., Lewandowski, J., Li, A., Martí, E., Miller, M., Milner, A. M., Neil, K., Orsini, L., Packman, A. I., Plont, S., Renteria, L., Roche, K., Royer, T., Schmadel, N. M., Segura, C., Stegen, J., Toyoda, J., Wells, J., Wisnoski, N. I., and Wondzell, S. M.: ESSD, 2019 - Data Collection https://doi.org/10.4211/hs.f4484e0703f743c696c2e1f209abb842, 2019.

Ward, A. S., Gooseff, M. N., and Singha, K.: Imaging hyporheic zone solute transport using electrical resistivity, Hydrol. Process., 24, 948-953, https://doi.org/10.1002/hyp.7672, 2010a.

Ward, A. S., Gooseff, M. N., and Singha, K.: Characterizing hyporheic transport processes-Interpretation of electrical geophysical data in coupled stream-hyporheic zone systems during solute tracer studies, Adv. Water Resour., 33, 1320-1330, https://doi.org/10.1016/j.advwatres.2010.05.008, 2010b.

Ward, A. S., Fitzgerald, M., Gooseff, M. N., Voltz, T. J., Binley, A. M., and Singha, K.: Hydrologic and geomorphic controls on hyporheic exchange during base flow recession in a headwater mountain stream, Water Resour. Res., 48, W04513, 2012.

Ward, A. S., Gooseff, M. N., Voltz, T. J., Fitzgerald, M., Singha, K., and Zarnetske, J. P.: How does rapidly changing discharge during storm events affect transient storage and channel water balance in a headwater mountain stream?, Water Resour. Res., 49, 54735486, https://doi.org/10.1002/wrcr.20434, 2013a.

Ward, A. S., Gooseff, M. N., and Singha, K.: How does subsurface characterization affect simulations of hyporheic exchange?, Ground Water, 51, 14-28, https://doi.org/10.1111/j.17456584.2012.00911.x, 2013b.

Ward, A. S., Payn, R. A., Gooseff, M. N., McGlynn, B. L., Bencala, K. E., Kelleher, C. A., Wondzell, S. M., and Wagener, T.: Variations in surface water-ground water interactions along a headwater mountain stream: Comparisons between transient storage and water balance analyses, Water Resour. Res., 49, 3359-3374, https://doi.org/10.1002/wrcr.20148, 2013c.

Ward, A. S., Schmadel, N. M., Wondzell, S. M., Harman, C. J., Gooseff, M. N., and Singha, K.: Hydrogeomorphic controls on hyporheic and riparian transport in two headwater mountain streams during base flow recession, Water Resour. Res., 52, 1479-1497, 2016.

Ward, A. S., Kelleher, C. A., Mason, S. J. K., Wagener, T., McIntyre, N., McGlynn, B., Runkel, R. L., and Payn, R. A.: A software tool to assess uncertainty in transient-storage model param- 
eters using Monte Carlo simulations, Freshw. Sci., 36, 195-217, https://doi.org/10.1086/690444, 2017a.

Ward, A. S., Schmadel, N. M., Wondzell, S. M., Gooseff, M. N. and Singha, K.: Dynamic hyporheic and riparian flow path geometry through base flow recession in two headwater mountain streamcorridors, Water Resour. Res., 53, 3988-4003, https://doi.org/10.1002/2016WR019875, 2017b.

Ward, A. S., Schmadel, N. M., and Wondzell, S. M.: Simulation of dynamic expansion, contraction, and connectivity in a mountain stream network, Adv. Water Resour., 114, 64-82, https://doi.org/10.1016/j.advwatres.2018.01.018, 2018a.

Ward, A. S., Morgan, J. A., White, J. R., and Royer, T. V.: Streambed restoration to remove fine sediment alters reach-scale transient storage in a low-gradient 5 th order river, Indiana, USA, Hydrol. Process., 32, 1786-1800, https://doi.org/10.1002/hyp.11518, 2018 b.

Ward, A. S., Schmadel, N. M., and Wondzell, S. M.: Time-Variable Transit Time Distributions in the Hyporheic Zone of a Headwater Mountain Stream, Water Resour. Res., 54, 2017-2036, https://doi.org/10.1002/2017WR021502, 2018c.

Ward, A. S., Zarnetske, J. P., Baranov, V., Blaen, P. J., Brekenfeld, N., Chu, R., Derelle, R., Drummond, J., Fleckenstein, J. H., Garayburu-Caruso, V., Graham, E., Hannah, D., Harman, C. J., Herzog, S., Hixson, J., Knapp, J. L. A., Krause, S., Kurz, M. J., Lewandowski, J., Li, A., Martí, E., Miller, M., Milner, A. M., Neil, K., Orsini, L., Packman, A. I., Plont, S., Renteria, L., Roche, K., Royer, T., Schmadel, N. M., Segura, C., Stegen, J., Toyoda, J., Wells, J., Wisnoski, N. I., and Wondzell, S. M.: Colocated contemporaneous mapping of morphological, hydrological, chemical, and biological conditions in a 5th-order mountain stream network, Oregon, USA, Earth Syst. Sci. Data, 11, 15671581, https://doi.org/10.5194/essd-11-1567-2019, 2019.

White, D. S., Journal, S., American, N., and Society, B.: Perspectives on defining and delineating hyporheic zones, J. North Am. Benthol. Soc., 12, 61-69, 1993.
Wlostowski, A. N., Gooseff, M. N., Bowden, W. B., and Wollheim, W. M.: Stream tracer breakthrough curve decomposition into mass fractions: A simple framework to analyze and compare conservative solute transport processes, Limnol. Oceanogr.Meth., 15, 140-153, https://doi.org/10.1002/lom3.10148, 2017.

Wohl, E. and Merritt, D.: Prediction of mountain stream morphology, Water Resour. Res., 41, 1-10, https://doi.org/10.1029/2004WR003779, 2005.

Wohl, E. and Merritt, D. M.: Reach-scale channel geometry of mountain streams, Geomorphology, 93, 168-185, https://doi.org/10.1016/j.geomorph.2007.02.014, 2008.

Wondzell, S. M.: Flux of Ground Water and Nitrogen Through the Floodplain of a Fourth-Order Stream, PhD Dissertation. Oregon State University, 113 pp., 1994.

Wondzell, S. M.: Effect of morphology and discharge on hyporheic exchange flows in two small streams in the Cascade Mountains of Oregon, USA, Hydrol. Process., 20, 267-287, 2006.

Wondzell, S. M.: The role of the hyporheic zone across stream networks, Hydrol. Process., 25, 3525-3532, https://doi.org/10.1002/hyp.8119, 2011.

Wondzell, S. M. and Gooseff, M. N.: Geomorphic Controls on Hyporheic Exchange Across Scales: Watersheds to Particles, in: Treatise on Geomorphology, vol. 9, edited by: Schroder, J. and Wohl, E., 203-218, Academic Press, San Diego, CA, 2014.

Zarnetske, J. P., Gooseff, M. N., Brosten, T. R., Bradford, J. H., McNamara, J. P., and Bowden, W. B.: Transient storage as a function of geomorphology, discharge, and permafrost active layer conditions in Arctic tundra streams, Water Resour. Res., 43, W07410, 2007. 